\title{
DECLINING HOMICIDE IN NEW YORK CITY: A TALE OF TWO TRENDS
}

\section{JEFFREY FAGAN," FRANKIIN E. ZIMRING,"* AND JUNE KIM"*}

The mass media pay plenty of attention to crime and violence in the United States, but very few of the big stories on the American crime beat can be classified as good news. The driveby shootings and carjackings that illuminate nightly news broadcasts are the opposite of good tidings. Most efforts at prevention and law enforcement seem more like reactive attempts to contain ever expanding problems rather than discernable public triumphs. In recent American history, crime rates seem to increase on the front page and moderate in obscurity.

The recent decline in homicides in New York City is an exception to the usual pattern, the most celebrated example of crime-news-as-good-news in decades. No doubt part of the public attention can be explained because the story took place in the media capital of the United States. But more than location made the New York story newsworthy. The drop in homicides was both large and abrupt-the homicide rate in the nation's largest city fell $52 \%$ in five years. Further, changes in police manpower and strategy are widely believed to have contributed to the decline. If this drop can be plausibly tied to enforcement

- Professor, School of Public Health, and Visiting Professor, School of Law, Columbia University. This research was a joint effort of the Center for Violence Research and Prevention at the Columbia School of Public Health, and the Earl Warren Legal Institute, University of California at Berkeley. The authors thank Marlene Pantin, Carolyn Pinedo, and Tamara Dumanovsky for invaluable research assistance. We are grateful to the New York City Police Department and the New York City Department of Health for their assistance and generosity.

“ William G. Simon Professor of Law, and Director, Earl Warren Legal Institute, School of Law, University of California at Berkeley.

.* Research Assistant, Earl Warren Legal Institute, School of Law, University of California at Berkeley. 
activities, it would be the most conspicuous success of city police deployment policies in the twentieth century.

This article reports our attempt to assess the extent and causes of the five-year decline in life threatening violence in New York City. Part I puts the homicide decline in a variety of statistical contexts, comparing the drop to previous New York experience and to the experiences of other cities in the United States. Part II examines changes in patterns of homicide during the decline in search of clues about causes. Part III examines available data on crime trends and trends in crime-related phenomena over the years when homicide increased and declined. Did many crime categories fall, and by how much? Was the decline concentrated in a few categories or spread evenly across the spectrum of felony crime? What were contemporaneous trends in drug use, demography, and incarceration? Part IV reviews some explanations of the decline.

\section{How BIG A DROP?}

This section places the five-year decline in New York City homicide in a variety of historical contexts. How large is this drop compared to previous periods in the history of New York City? Is a drop this substantial a typical event in the history of a big city?

One important element of context for studying the New York City experience is the recent history of homicide rates in the United States. Figure 1.1 provides national level homicide rates by year over the period 1950-95.

After steady to declining trends until the early 1960s, the homicide rate doubled in the period from 196474 from just under 5 per 100,000 at the beginning of that period to just under 10 per 100,000 in 1974 . After 1974, the trend over time appears to be fluctuations around the 1974 high. Homicide dropped somewhat in the mid-1970s then climbed back up to just above 10 per 100,000 in 1980, dropped in the early 1980s, then climbed back up close to the 1980 high point in the early 1990s only to drop off again after 1991.

If all the homicide trends since 1964 were forced into a single trend line, the direction of the trend would be upward. If 

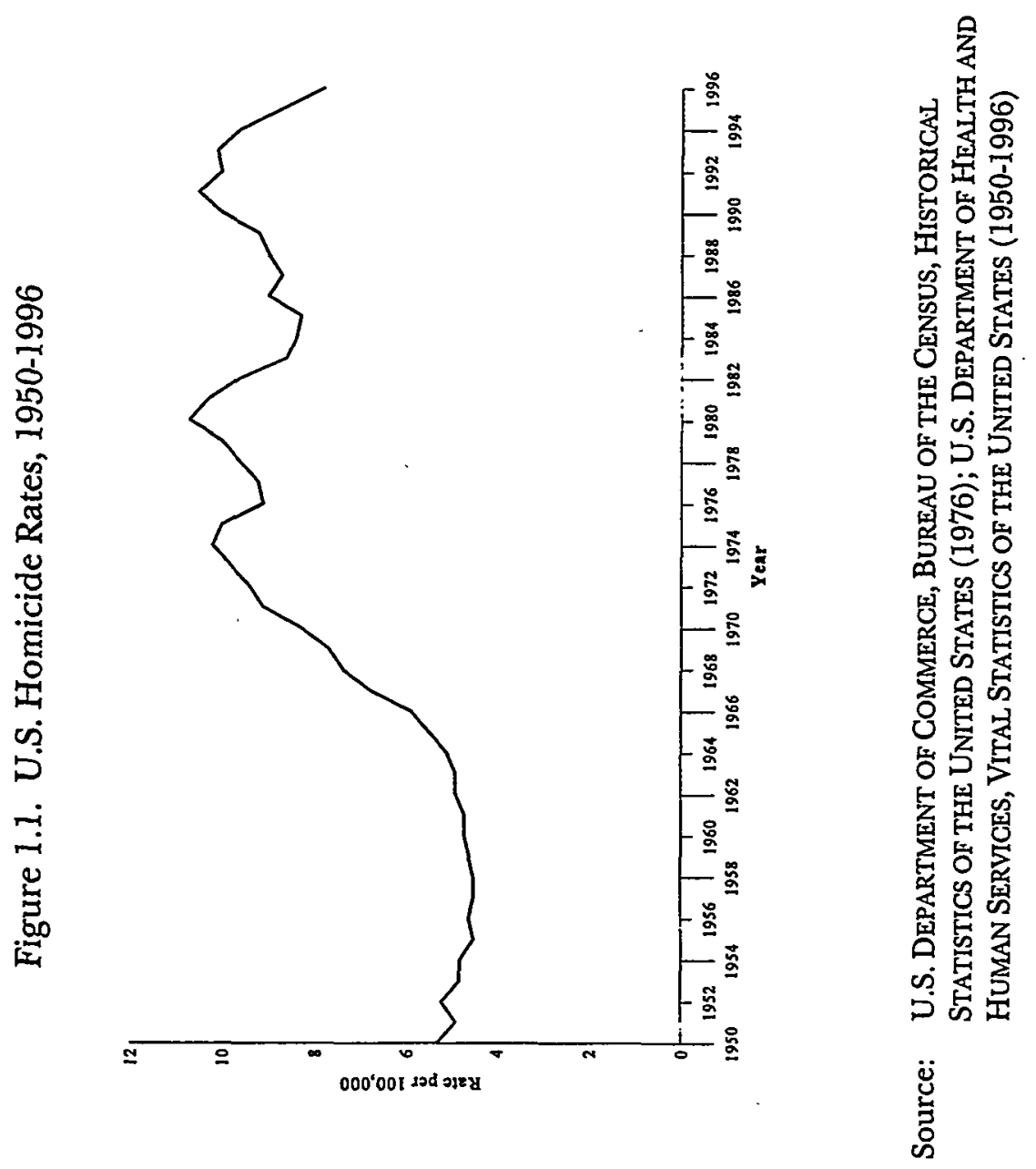
the doubling of rate prior to 1975 is plotted separately, however, the two decades since 1975 represent a trendless fluctuation down from the new peak rate of 10 per 100,000 per year and then back up. By 1995, the homicide rate had dropped back near but not yet below the twenty-year low set in 1984 .

The New York City history can be briefly stated. In its relative and absolute magnitude, the homicide drops after 1992 were by far the largest in the postwar history of New York City. The second largest percentage drop was 25\% from 1981-1985. The number of lives involved is even more impressive, with more than 1,100 fewer homicide victims in New York City in 1996 than in 1992. This reduction in homicide far exceeded the total number of homicides the city experienced each year in the 1950 s and early 1960 s.

The comparison of this New York experience with the experience of other cities is a more complicated story. Figure 1.2 begins the analysis by reporting on the largest five-year declines in homicides reported since 1945 in each of the fifteen largest cities in the United States as of 1950.

The five-year records for big cities vary from a $61 \%$ decline in Pittsburgh through a $15 \%$ decline in Chicago. The median decline was $40 \%$ and seven cities reported highest decline percentages between $43 \%$ and $38 \%$. The New York decline is the third highest for the major cities, behind Pittsburgh, equal to Houston, and about $25 \%$ larger than the cluster of city records around $40 \%$. Based on straight arithmetic, the New York experience is not unprecedented, but is a higher percentage drop than twelve of the nation's fifteen biggest cities have experienced in a five-year span.

There are two other city comparisons that help to illuminate the relative standing of the New York City decline. Figure 1.3 drops the constraint of a five-year span and searches for the largest homicide declines in a decade or less for each of the thirteen largest cities in 1950.

New York City's five-year drop maintains its position as the third largest in this comparison, but a much larger number of cities record declines of the same general magnitude of New 
$\frac{\infty}{8}$

幽

ขึ

5

8

垈

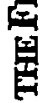

$2 \quad 2$

ह

in

$\infty$ क

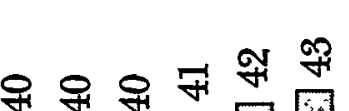

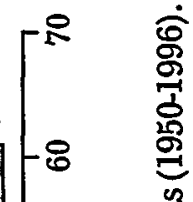

1

m

m (1)
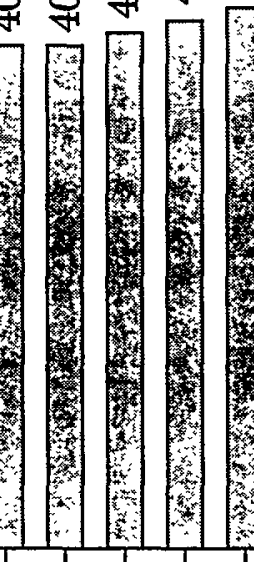

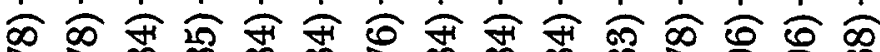

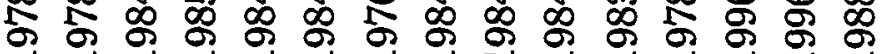

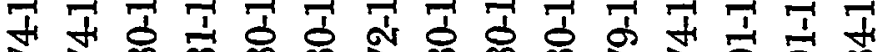

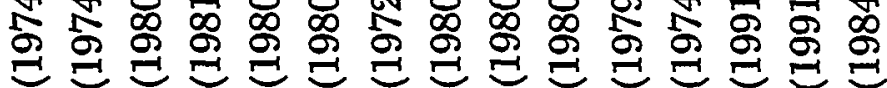

융 웡

矛步

\&

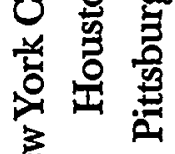

空

- 10

-욱 总

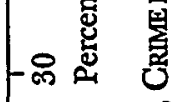

ণj 


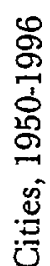

ڤุ

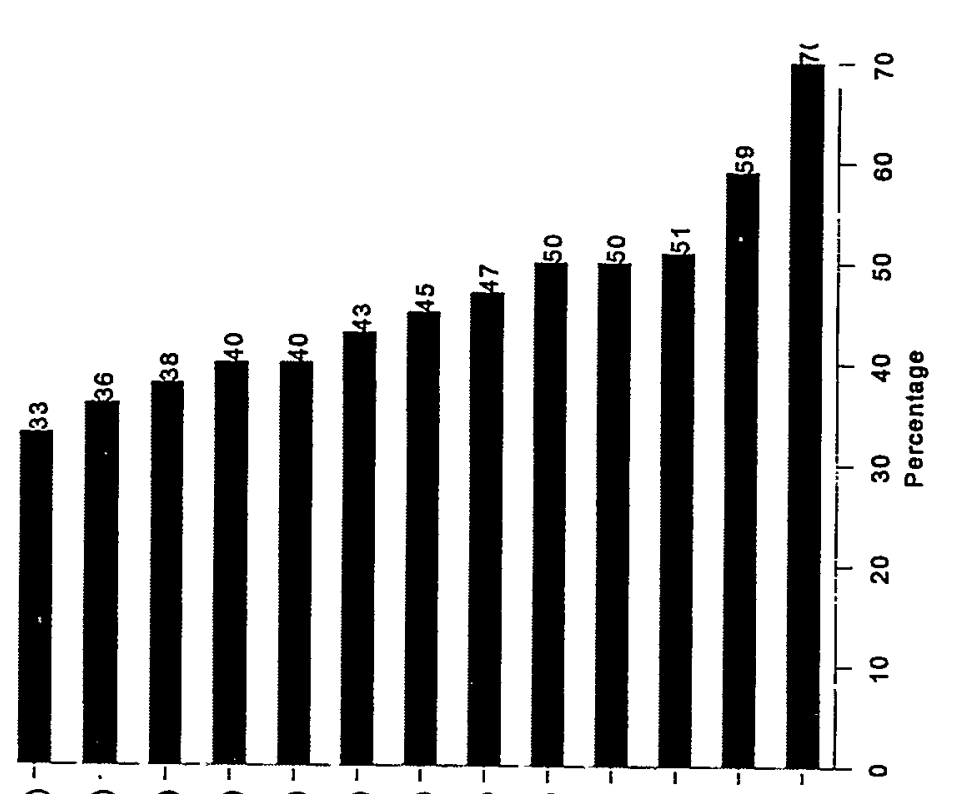

苟

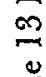

$\cong$

ฮ్ర

$\pi$

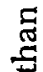

岁

$\Xi$

$\stackrel{\mathscr{g}}{\Xi}$

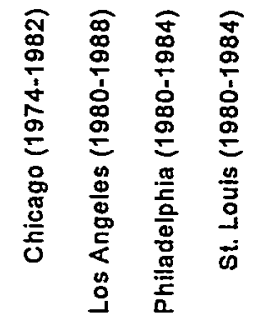

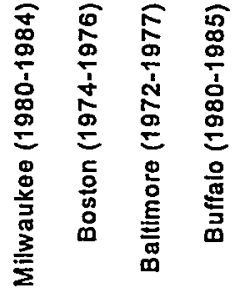

今

ְై

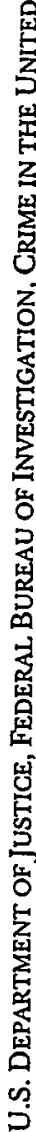

نัّ 
York's 51\%. It is worth noting, however, that the very largest cities in the United States other than New York Gity have more modest percentage declines than the smaller cities. New York City's population greatly exceeds Houston's, the next largest city with a similar relative homicide decline.

Figure 1.4 tests the five cities with the highest five-year declines against the hypothesis that an abnormally high homicide rate for a short period of time is the reason for a large drop in the homicide rate. The low year in the largest five-year decline is compared to the mean rate in that city for the previous fifteen years.

Figure 1.4 helps the observer tell the difference between a big drop that occurs when a city rate returns to near historically normal rates from an atypical high level and declines that still look dramatic when compared with homicide in a city over the long term.

Three of the five largest declines (including New York City) represent a substantial reduction from the average rate in the previous fifteen years. For Pittsburgh, Houston, and New York City, it is difficult to argue that the drops recorded were merely regression from abnormally high rates. The Boston decline, by contrast, was only to a point $11 \%$ below the previous long-term mean. Regression is a much more likely explanation in that case.

There is one further measure of possible regression relevant to our inquiry. In an era when very wide swings in rates of criminal homicide occur, sharp downward movements in the homicide rate might be expected after sharp upward movements. The theory here is that some downward momentum might be expected after a steep climb in homicide rates for the same reason that rollercoasters tend to drop faster when they have climbed to a great height. The $59 \%$ drop in Houston homicides after 1991 came after a sharp increase in rate. Between 1987 and 1991, Houston's homicide rate climbed from 18.5 per 100,000 to $36.3-\mathrm{a} 96 \%$ increase. Viewed against this background, both the swiftness and the extent of the decline is less astonishing. When measured against the previous low point 


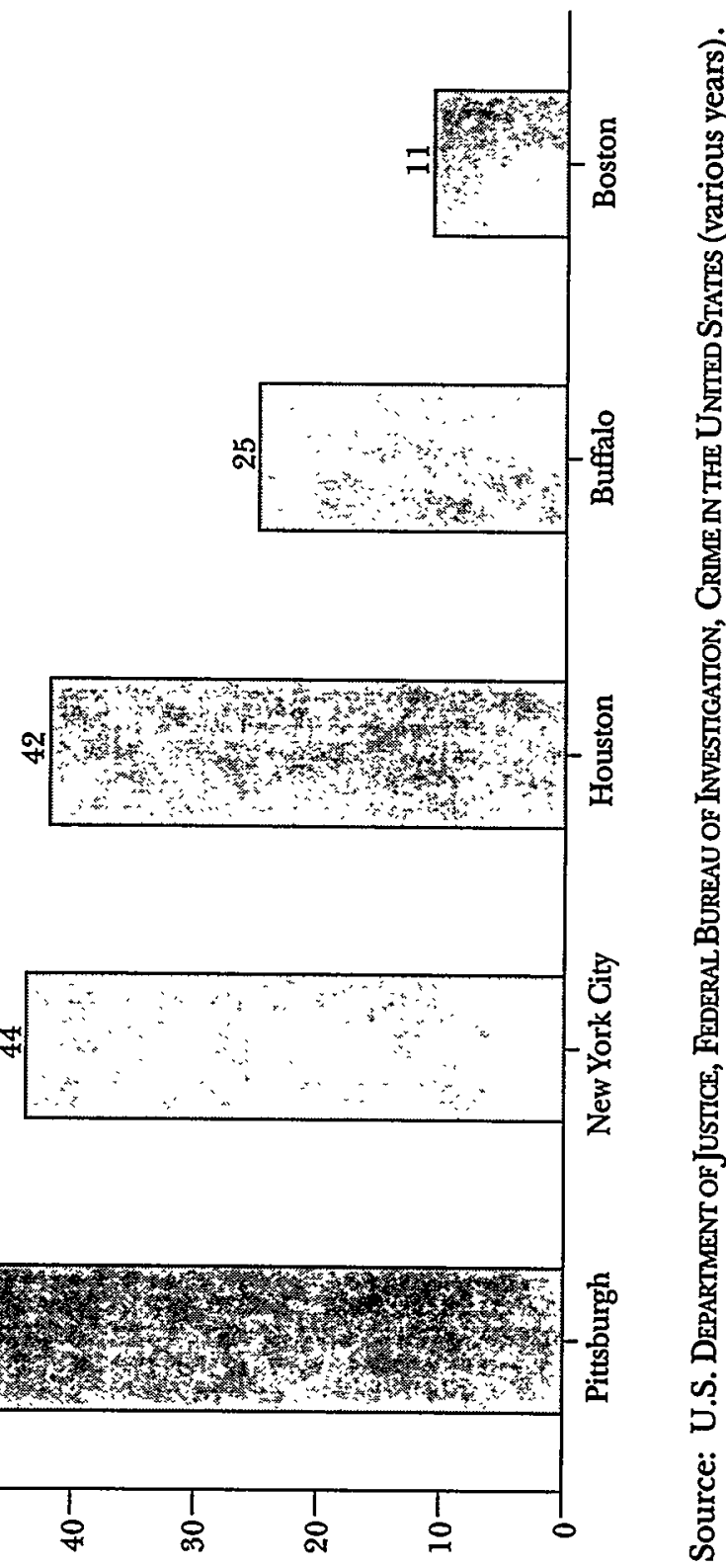


in 1987, the Houston homicide rate had declined $19.6 \%$ instead of $59 \%$, from 18.5 to 14.9 per 100,000 . Moreover, the first year in which the Houston homicide was lower than its 1987 level was 1995, three years after the decline started. The real possibility of cyclical variations means that Houston may not have broken out of its long-term pattern until late in the current decline, and that the current homicide level is only modestly lower than the previous low. Similar measures can be found in Dallas, where a $58 \%$ decline in homicide brought the 1996 homicide rate to 23\% under the city's 1983 rate.

How does New York City fare on this measure? To use the rollercoaster metaphor, the climb in New York City was not as steep prior to the post-1991 drop, so that less of the New York decline seems likely to be merely cyclical. Between 1985 and 1991, New York City's homicide rate had increased 56\% from 17.5 to 27.3 per 100,000 . The homicide rate in 1996 was $23 \%$ below the 1985 rate, so that about half of the decrease noted by 1996 was outside the range of cyclical variations experienced in the recent past in New York City.

Still, much of the New York decline could have been cyclical, and this possibility constrains our capacity to explain the homicide decline on other grounds, or to time with precision when New York homicide started behaving in non-cyclical fashion. As late as the end of 1995, the New York homicide rate was within $10 \%$ of its 1985 level. The rate of lethal violence broke important new ground only after 1995 or 1996.

A number of conclusions can be drawn from this brief excursion into the natural history of homicide rates in U.S. cities. The percentage decline experienced in New York in five years is quite large but by no means unprecedented in major cities. The largest five-year drop in the average major city since the Second World War is about $40 \%$-a figure $20 \%$ smaller than New York City's. When declines over a six-to nine-year span are allowed, six other cities produce declines of a magnitude similar to the New York experience at some point in post-war history. These declines usually come after periods of general increase in homicide rates. The most common year as a starting point for a 
city's record decline was 1980, the highest year in U.S. homicide for at least a half century.

Declines of the magnitude experienced in New York City are not unprecedented, but they are not very common either. Only two other large cities exceed the New York percentage decline at any time in the post-war era. The New York record far exceeded the short-term drops recorded in any other city with a population of more than two million. And the large difference between the 1996 homicide rate in New York Gity and the previous fifteen years of homicide make a strong case against regression as a major part of the explanation for the five-year decline. So the decline is large by historical standards and not merely an echo of a sharp but temporary previous rise. None of this goes directly to the question of what may have caused the New York drop. We have first attempted to get an accurate measure of the size of the effect we are studying.

The next section shifts attention from the number of homicides occurring in New York City to an account of the different trends for different types of killings. The theory is that shifts in the types of homicides that take place can provide clues as to why the change has occurred.

\section{The NATURE OF THE HOMICIDE DECLINE}

The homicide statistics discussed in the previous section are an aggregation of many different types of attack, many different community areas, and many different population groups that live in New York City. This section will analyze the types of homicide that have changed the most, in order to search for clues as to the probable causes of the changes. The analysis reports on cross-tabulations of New York City homicide over time by borough, by weapon, and by demographic groups in the city. Each of these disaggregations produces findings we believe to be of major importance in interpreting the New York story.

\section{A. VARIATIONS BY BOROUGH}

One important approach to disaggregating New York homicide rates is by borough. The four major boroughs in the cityBrooklyn, Manhattan, Queens, and the Bronx-each have a 
population that would rank in the top ten U.S. cities. These four urban assemblages differ importantly from each other in economy, culture, population, and many other community characteristics. A natural question to ask is whether the homicide decline has been spread evenly over these four clusters or has been uneven in impact.

Figure 2.1 approaches this question by taking the average annual homicide count for each of the four large boroughs for the years 1985, 1986, and 1987 and expressing each year's homicide over the period 1985-95 as a percentage of that base. If the homicide count in Manhattan during 1989 was $25 \%$ more than the annual average during 1985-1987, the index for 1989 homicide in Manhattan will be 125 on the figure. This strategy is adopted to facilitate comparing the trends over time in the four boroughs. Staten Island is deleted from the analysis.

The four different boroughs differ importantly in the patterns observed while homicide rates grew in New York City, but are much less divergent during the years of decline. The peak volume of homicide in Manhattan was $35 \%$ greater than the 1985-1987 average, while Queens and Brooklyn grew 64 and $69 \%$ and the Bronx grew 93\%. These were large differences in growth rate that were accompanied by a slight difference in timing. The peak year in Manhattan and the Bronx was 1990, while Brooklyn and Queens had their highest levels in 1991. Still, the temporal pattern during the late 1980s and early 1990s was pretty consistent across boroughs.

The boroughs are even more parallel in the period of decline. Even though the increases were very uneven across the boroughs, each of them experienced close to a $50 \%$ drop from the high value of the decade by 1995. The 1995 volume of homicide in the four boroughs ranges from $47 \%$ of the high for the Bronx to $50.6 \%$ of the high value in Queens. The extent of the increase had no discernable impact on the proportionate homicide decline. This pattern seems the obverse of the saying that a rising tide lifts all boats. 


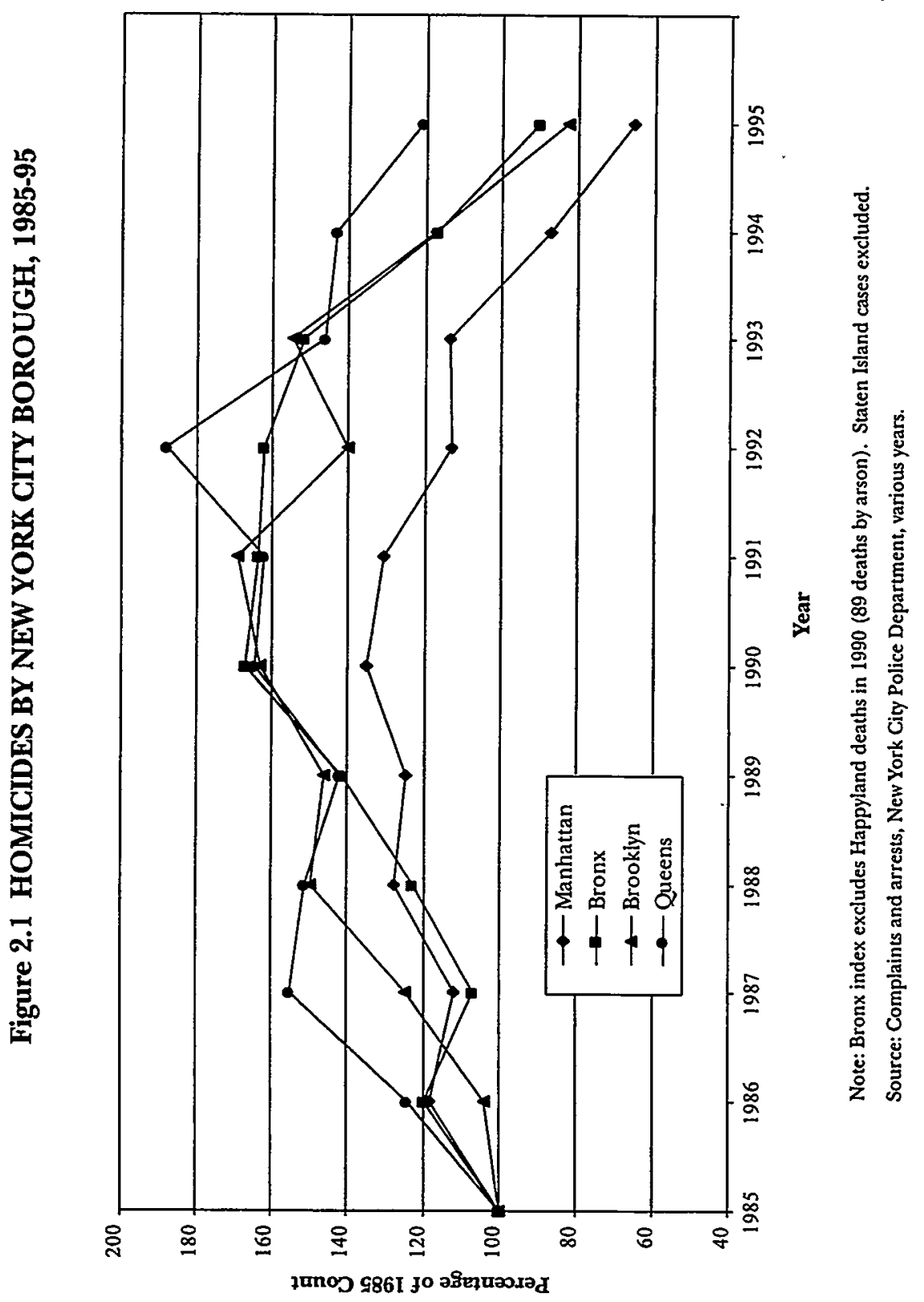




\section{B. PATTERNS BYWEAPON}

The significant division of homicides in New York by weapon is between gunshot deaths and all others. The best data available on homicide by weapon over time comes from the Office of the Medical Examiner, which includes a small category of justifiable killings but otherwise should be parallel to the police data. Figure 2.2 shows the pattern by weapon using the 675 nongun killings in 1995 and the 834 gun killings in that year as a base of 100 to track trends over time. The nongun total for 1990 has been adjusted by deleting 85 of the 86 killings from the Happyland Social Club fire, in effect counting that episode as one homicide. This is done to smooth out the long-term trend curve.

In Figure 2.2, the patterns for gun and nongun killings are sharply different. Nongun killings drift downward from the beginning, interrupted only in 1990 by the 86 fire deaths in a single incident. By 1992, nongun deaths had dropped by $35 \%$, and this trend continued through to 1996. Gun deaths meanwhile doubled between 1985 and 1991 and did not fall back to the 1985 level until 1995.

The gun death pattern is well known, and the rise in homicide by gun was large enough in the late 1980s and early 1990s to increase the total level of homicide until 1990 in the medical examiner's data, and to keep total homicide high through 1993. What the gun trends obscure is the steadiest long-term trend in New York City-a downward movement in homicides by all means other than gun that began after 1986 and gathered momentum steadily throughout the late 1980s and early 1990s. By $1992,70 \%$ of the total decline in nongun killings noted in the entire 1985-1996 period had already occurred. The declines after 1992 in nongun killings appear to have been a continuation of the eight years of previous decreases.

There are thus two dynamic and different patterns in the data on homicide by weapon. Gun killings first increase then fall back to previous levels. Nongun killings trend down from start to finish. The magnitude of the nongun trend is substantial and its timing is well documented. But it has not previously been noticed. 


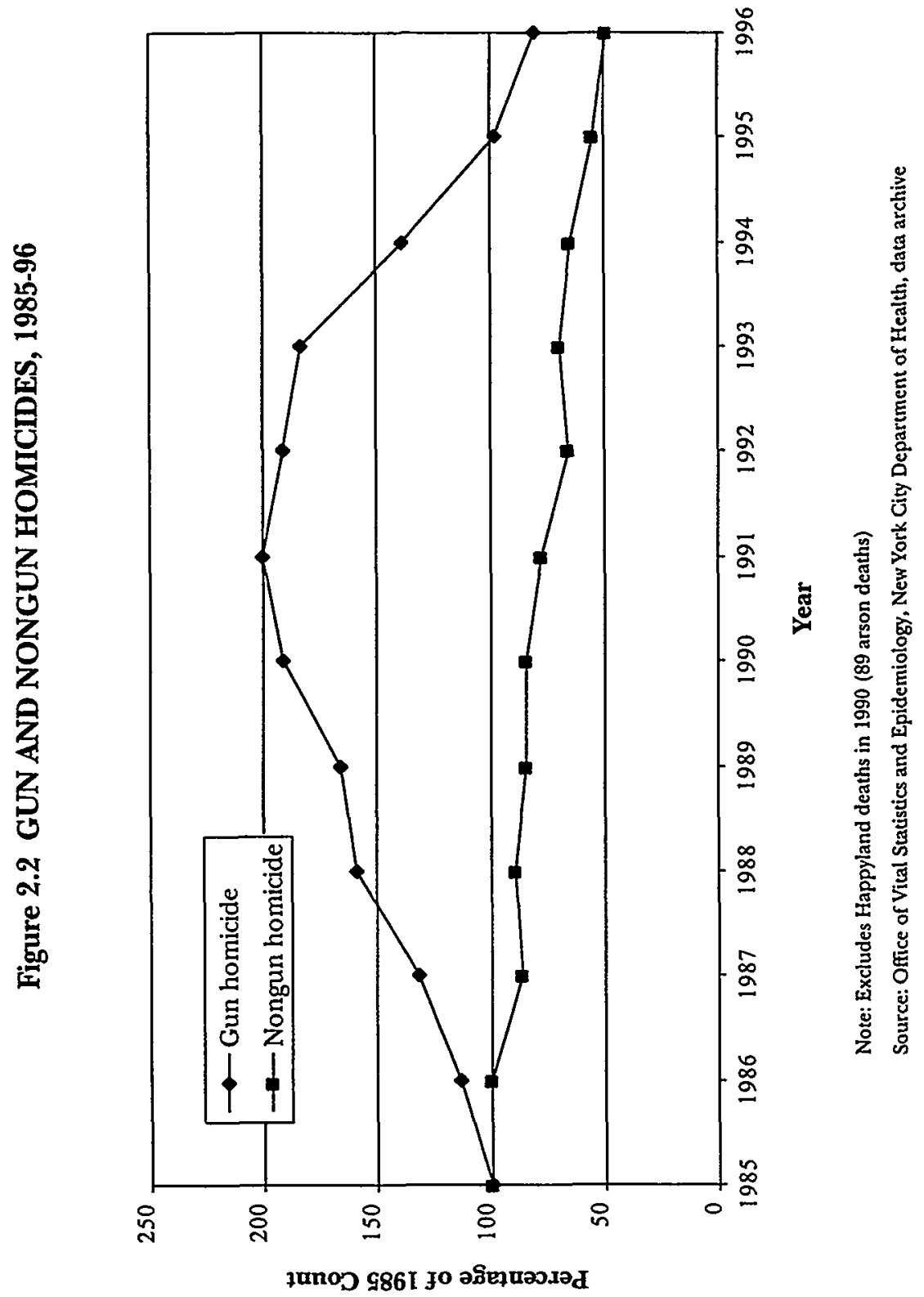




\section{THE DEMOGRAPHICS OF HOMICIDE}

The distinct patterns of gun and nongun homicide raise questions about whether these patterns were similarly distributed among the population of homicide victims. Using the Medical Examiner records, we disaggregated characteristics of gun and nongun homicide victims by age, sex, and race. The demographic patterns of gun and nongun homicide throughout this period tell two interesting stories. First, the homicide trends for women differ from the patterns for men, a gender contrast consistent with prior studies on the stability of female homicide. Second, changes in adolescent homicide rates were accompanied by parallel but less dramatic changes among the older population. This trend varies from the national picture of steadily declining rates among older groups.

\section{1. $\operatorname{Sex}$}

Homicide rates for women were lower overall from 1985 through 1995, consistent with homicide trends historically. However, the trends in gun and nongun homicides for males and females differed in the magnitude, timing, and duration of change over the period. Figure 2.3 shows that gun homicides by women increased by $68 \%$ during this period, compared to an increase of over $105 \%$ for males. The timing and duration of the increase for females was similar to that of males. Rates for women peaked in 1991, the same year as males, and sustained their peak rate for approximately three years before dropping sharply in 1994. By 1995, gun homicides for females had dropped $5 \%$ below their 1985 levels, but remained $10 \%$ above the 1985 levels for males.

The steady decline in nongun homicides described earlier was not consistent for men and women. Figure 2.3 shows that there were steady declines for both groups, but the decline was greater for men than women. By 1995, nongun homicide rates for males were $45 \%$ below their 1985 rates. ${ }^{1}$ However, the rates

\footnotetext{
' The 1990 spike for male nongun homicides most likely reflects the 89 deaths in the Happyland Social Club fire. However, we could not adjust the rates for these deaths since data were not available on the gender composition of the victims of that fire.
} 


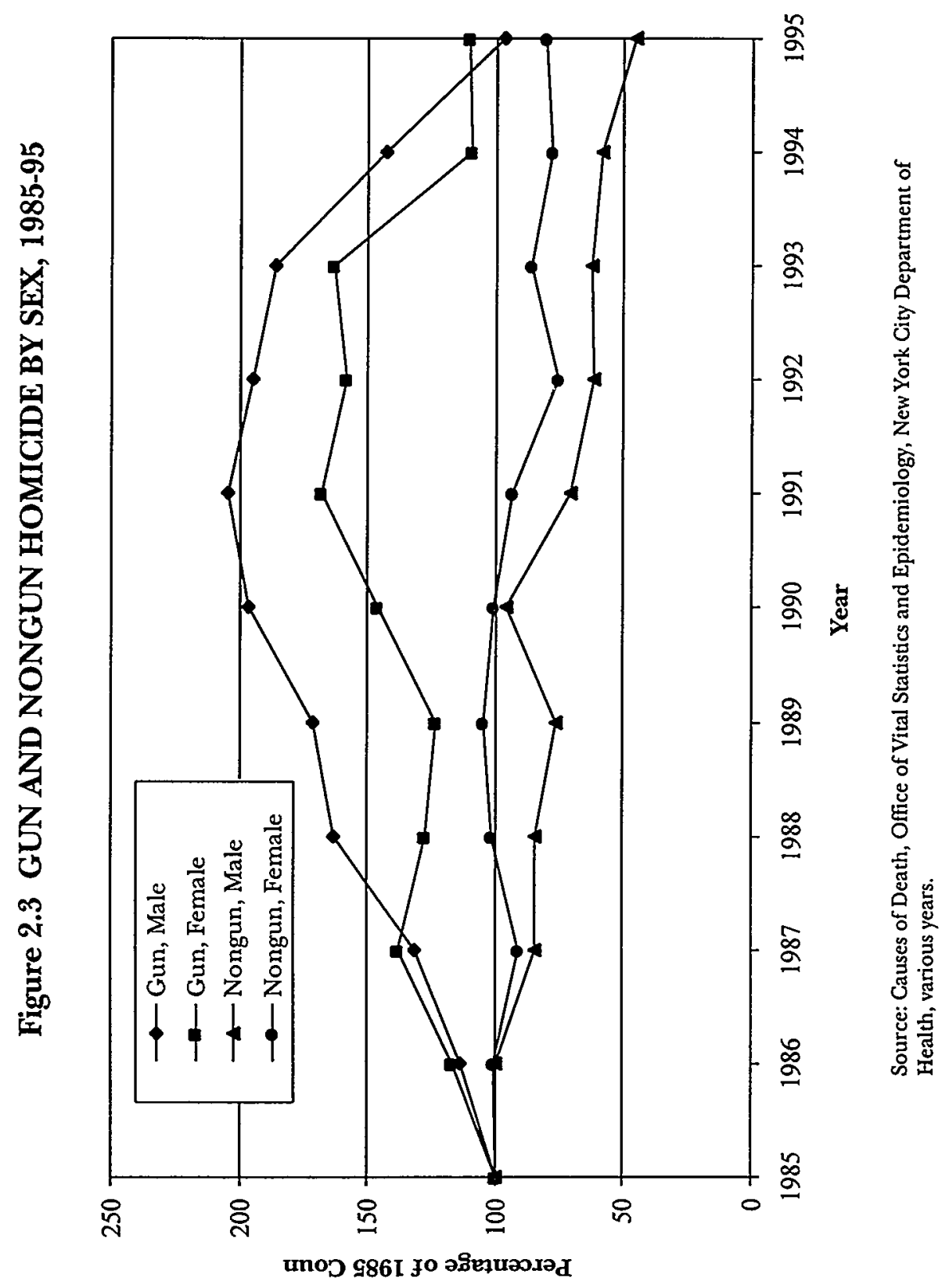


for women declined far less. After reaching a low of $25 \%$ below their 1985 rate in 1992, they settled at about $80 \%$ by 1995 . In fact, the overall trend for women has not changed since 1992.

\section{Age}

Much of public and scholarly attention on violence in the past decade has focused on the increase in gun homicides by adolescents. ${ }^{2}$ Trends nationwide show that gun homicide rates for adolescents increased during this period while gun homicide rates for persons over twenty-five years of age were declining. Figure 2.4 shows that while adolescent participation in gun homicide did rise sharply from 1985-1991, rates for other age groups also continued to rise during this period. ${ }^{3}$

Gun homicides by adolescents ages $15-19$ rose more quickly and sharply over this period. By 1991, the gun homicide rate for this group reached a peak of $176 \%$ above its 1985 rate. The other population groups also increased, peaking at approximately the same time at about $100 \%$ above their 1985 rates. Rates for the oldest population group, those thirty-five-years-ofage or more, rose slightly more slowly, peaking at $77 \%$ over their 1985 rate. Accordingly, adolescents became an active part of a homicide epidemic that spanned age groups.

The decline among adolescents was equally precipitous. By 1995, adolescent homicide counts declined to $25 \%$ above their 1985 base rate. All other population groups returned to their 1985 rates or declined below those rates.

${ }^{2}$ See, e.g., Alfred Blumstein, Youth Violence, Guns, and the Illicit Drug Industry, $86 \mathrm{~J}$. CRIM. LAW \& CRIMmOLOGY 10 (1995); Phillip Cook \& John Laub, The Unprecedented Epidemic in Youth Violence, in M. TONRY \& M. MOORE, YOUTH VIOLENCE (1998).

${ }^{3}$ We include only homicide victims ages 15 and above. The gun homicide counts for those 14-years-old and younger were extremely low during this period, and their participation in nongun homicide exceeded gun homicide by $50 \%$ or more. 


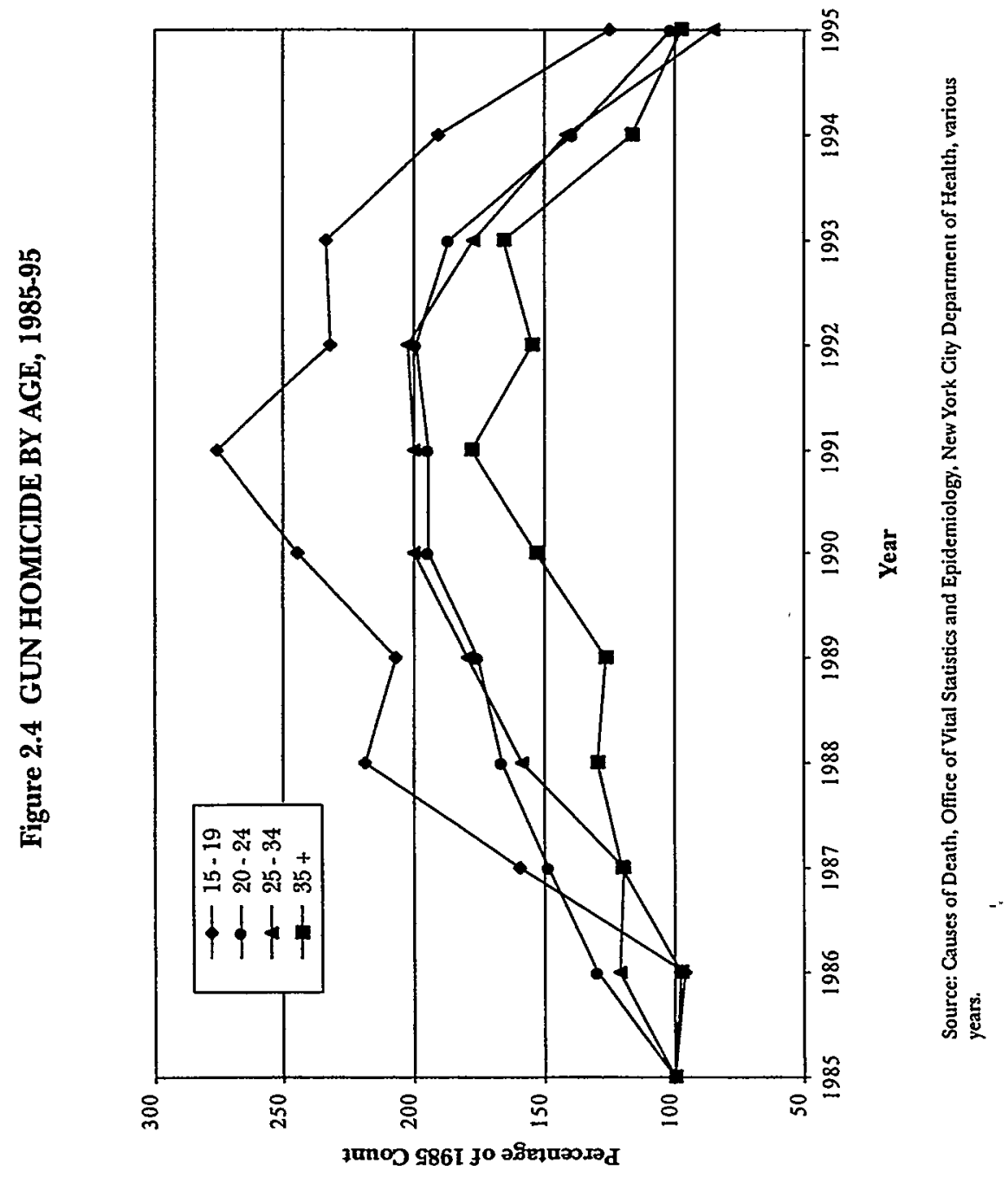




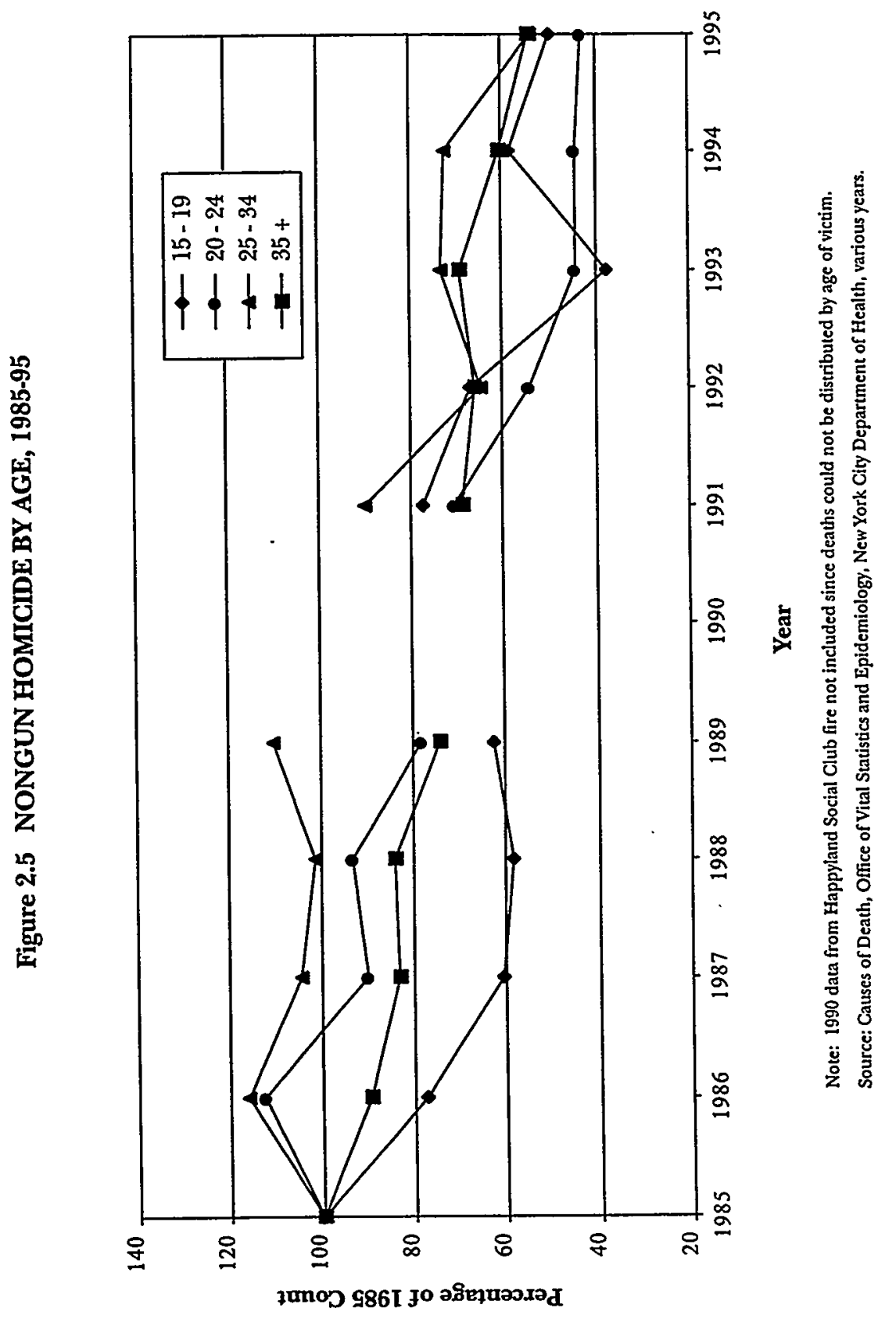


Figure 2.5 shows that the nongun homicide rates during this period declined for all age groups. We excluded the 1990 data, since age distributions of the Happyland Social Club fire victims were unavailable. The oldest and youngest age groups contributed proportionally to the nongun homicide decline from 1985-1989. By 1991, the decline was evident among all age groups.

\section{Race}

None of the data sources permitted detailed disaggregation of the homicide trends by race over the entire 1985-1995 period. Detailed data were available only for African-Americans; whites and Hispanics were not distinguished in the police or Medical Examiner data until after 1990. From the available data, there were no changes in the racial composition of the homicide population during this period. Data from several sources show that homicide rates among African-Americans were higher compared to others throughout the period from 1985-1995.

\section{CONCOMITANTS}

This section compares the city-wide homicide data developed in the previous section with trends in crime statistics and selected other social data widely believed to be linked to trends in lethal violence. City-wide data comparisons are presented because of the finding in the previous section that trends are consistent in time and, with one minor exception, in magnitude, over New York's four large metropolitan boroughs. The historical data

4 One data source does provide race-disaggregated information on weapon-related fatalities and injuries, but only from 1990-95. Sharp declines in firearm assault injuries and fatalities were observed for all races from 1990-95, according to the Injury Surveillance System of the New York City Department of Health. The surveillance system hierarchically combines case-level data on fatalities, hospitalizations, and emergency room admissions. OFFICE OF VITAL STATISTICS AND EPIDEMIOLOGY, SUMMARY OF VITAL STATISTICS, 1996, THE GTTY OF NEW YORK (1997). Firearm death and nonfatal injury rates declined by $50 \%$ or more for both Blacks and Hispanics from 1991 to 1995. Rates for whites also declined, but at a slower pace. Rates of nonfirearm deaths and injuries declined more slowly for all races during this period. 


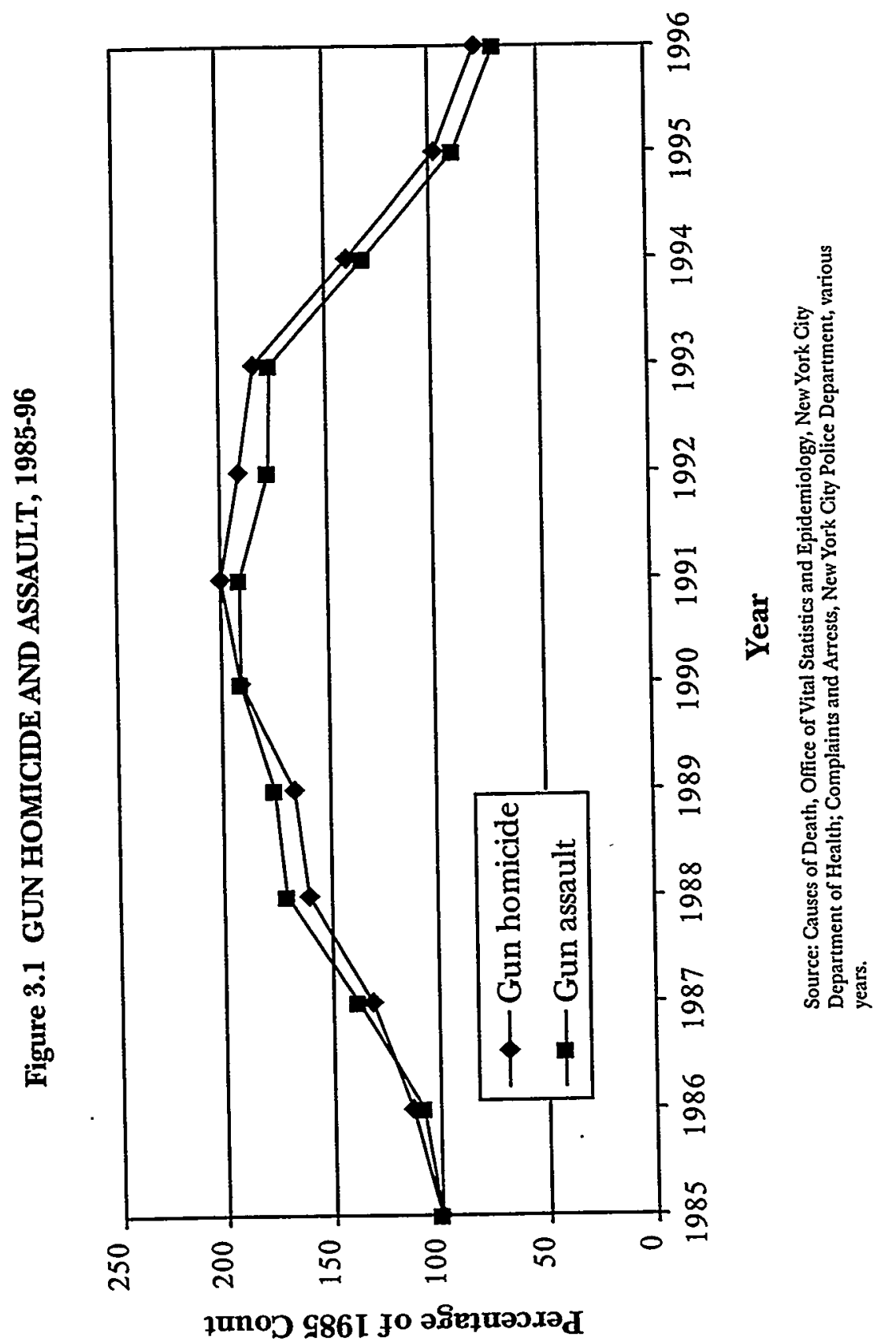


for gun and nongun violence is presented separately in this section because, as discussed in the previous section, gun and nongun homicides have distinctly different histories in the city.

The first part of this section compares homicide trends with trends in police reported assaults. The second part measures the trends in gun and nongun homicide with trends in other crimes.

\section{A. HOMICIDE AND ASSAULT DATA}

The pattern over time for firearms homicide and firearms assault is shown in Figure 3.1, with 1985 rates of shooting deaths and firearms assaults expressed as 100 and all other values normed to that scale.

The trends in police reported gun assaults and health department gun homicides are almost perfectly matched for the six years of increase to 1991, and for the decreases thereafter. In both timing and relative magnitude, the firearm assault trends match the firearm homicide trends. For this time period, trends in known firearm assaults are a very good index of trends in gun deaths. The case fatality rate of gun death per each ten gun assaults is stable over time. The increased level of firearm assaults, about 8,600 more known cases by 1990 and 1991, appears to be the mechanism that is driving the increase in gun fatalities, and the sharp drop in firearms assaults after 1993 seems to be the dynamic in the drop in firearms fatalities, although no strict test for causal ordering can be imposed on this data.

The data on nonfirearm aggravated assault trends and health department homicides by all means other than firearms are an extraordinary contrast to the firearms trends, as shown in Figure 3.2.

For most of the period, trends in nonfirearm aggravated assaults are a very poor index of trends in nonfirearm homicides: while the rate of death drops by half in the period from 19851995, the incidence of aggravated assault increases slightly. As a consequence of these sharply divergent trends, the case fatality rate drops from 16 per 1,000 in 1985 to 8 per 1,000 in 1995 . 


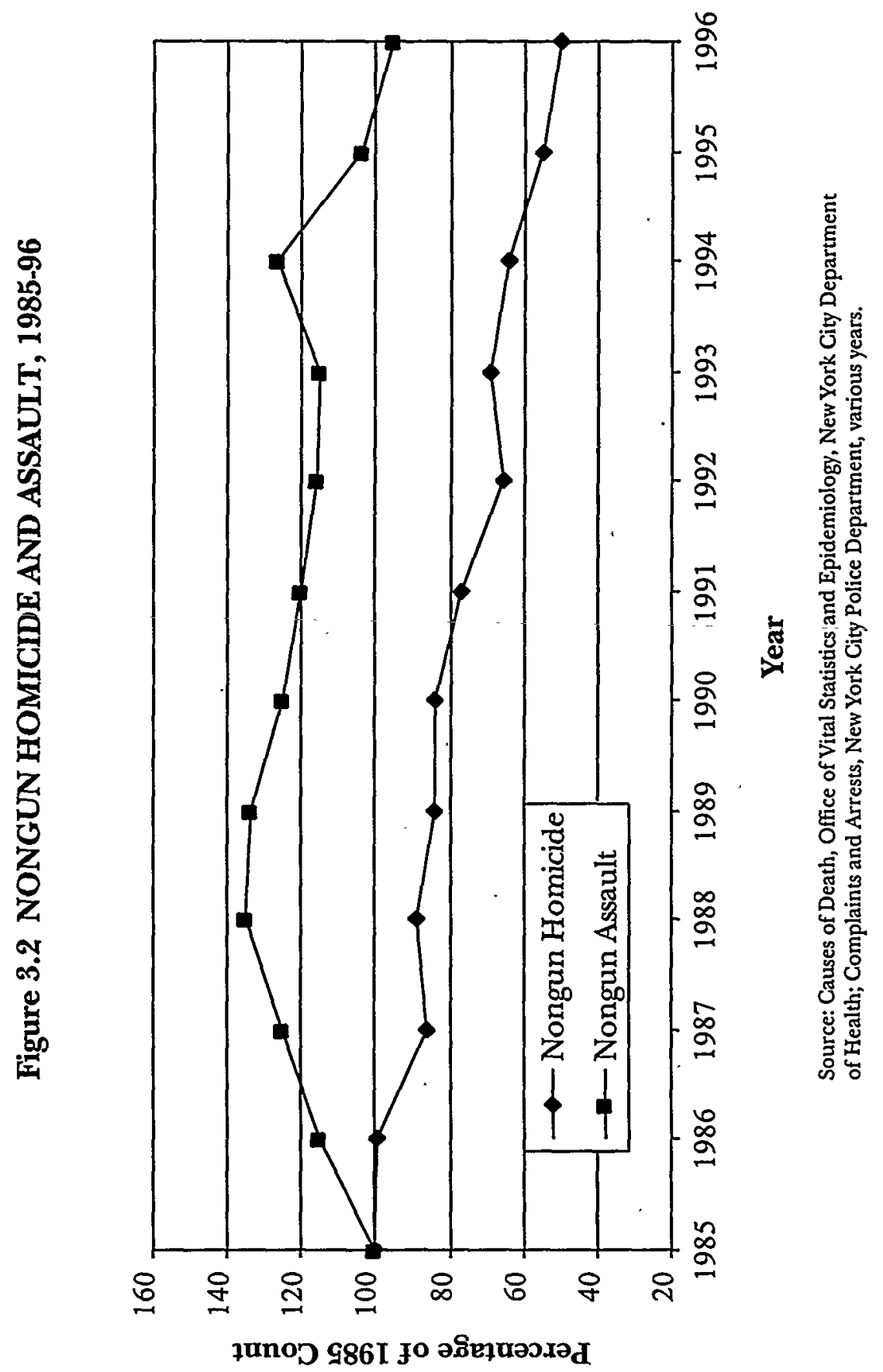


Obviously, any increase in total aggravated assaults during this period would have to be clustered in nonlife-threatening types of attack.

There is, however, a good reason to suppose that the growth in nongun aggravated assault cases is solely the product of greater willingness to classify borderline cases as the aggravated form of assault. At the national level, assault rates have grown over the same period much more quickly than any change in death rates could explain. So New York may simply be reflecting this national reclassification tendency. ${ }^{5}$

\section{One Trend or Two?}

An objection might be raised that the major finding of this study - the two separate trends in nongun and gun homicidesis really an artificial division of a unitary trend in violence over the period. The decline in nongun killings that starts in the mid-1980s is merely a shift from knife and personal force attacks to gun attacks. A proponent of this view might argue that there is no real reduction in violence to explain until after 1990, when total killings and presumably total high lethality attacks start to come down. Now that weapon-specific assault data has been added to the homicide story, this possible objection can be addressed with some economy.

The circumstantial evidence against this possibility comes from many separate sources. In the first place, while gun deaths doubled between 1985 and 1992, a shift in the volume of knife, other weapon, and personal force attacks that was large enough to reduce the nongun homicide rate by $35 \%$ would be expected to increase the gun death total by at least $150 \%$. This is because the case fatality rate in 1985 for gun assaults was 88 per 1,000 compared to 16 per 1,000 for the nongun assaults in New York in 1985. Given the instrumentality effects, the increase in firearms death was too small to fit with a displacement rather than decline in nongun violence. Nongun high lethality violence had to be coming down in the second half of the 1980 s.

\footnotetext{
${ }^{5}$ FRANKLIN ZimRING, AMERICAN YOUTH VIOLENCE $38-45$ (1998).
} 
A second problem with attributing the increase in gun incidents in New York City to the same violent incidents now occurring with guns rather than other weapons of attack is that this is inconsistent with the prevailing explanation for increased gun attacks in the late 1980s. The conventional wisdom is that gun incidents increased in large part because of turf conflict in the new crack trade. ${ }^{6}$ If new types of conflict explain much of the growth in gun violence, that would leave even less of the gun cases to explain as the effects of displacement.

A third problem with the late 1980 s pattern as a reciprocal displacement story is that the timing of the two trends is inconsistent with reciprocity. The two largest increases in gun homicide in the late 1980s occurred in 1988 and 1990. The biggest declines in nongun homicide happened in 1987 and 1992.

A fourth problem with a reciprocity explanation for the first seven years after 1985 is that the nongun homicide trends continued in a relatively uninterrupted fashion after 1992 as well. The magnitude of the drops in nongun killing after 1991 are quite consistent with the nongun pattern in the late 1980s, yet the increases in gun killings disappeared. An observer would have to maintain grossly different explanations for the front end years of the trend and the later years, despite the similarity in over-all pattern for the eleven years.

There is also evidence external to New York City that expanding gun homicide levels are not associated with declines in nongun violence. While gun homicide tends to increase more in up years than other weapon killings, and is also overrepresented in declines, the nongun trends tend to be flat rather than to fluctuate in the opposite direction.

Even granting the anomalous trend data for nongun assaults throughout the period, it should also be mentioned that the police nonfatal assault data just reviewed is also grossly in-

- See, e.g., Blumstein, supra note 2. See also PhilipPe J. Bourgois, IN SEArCh OF RESPECI: SEIIING CRACK IN EL BARRIO (1995).

${ }^{7}$ For the United States as a whole, see Franklin E. Zimring, Firearms and Federal Law. The Gun Control Act of 1968, 4 J. LEGAL STUD. 133 n.2 (1975). For youth violence, see Franklin E. Zimring, Kids, Guns, and Homicide. Policy Notes on an Age-Specific Epidemic, 59 LAW \& CONTEMP. PROBS. 25 (1996). 
consistent with any reciprocity explanation of the decline in nongun violence in the late $1980 \mathrm{~s}$. More reliable nonfatal assault data for the 1980s would help us put a more precise point on the independence of the gun and nongun trends, but the pattern seems clear on available evidence. A long decline in nonfirearms lethal violence continued throughout the period under study. In twelve years, the death rate dropped steadily until the 1996 rate was almost exactly half the 1985 rate.

Meanwhile, homicide by gun increased substantially and then decreased even more swiftly. The two homicide trends occurred in the same city but appear to be independent of each other, at least through the early 1990s and perhaps for the whole period under study.

\section{B. OTHER CRIME TRENDS}

Patterns of both robbery and property crime reflect the "two trend" finding in homicide, but the timing is not identical. Figure 3.3 shows the trends for firearm and other armed robberies for 1985-1996, again using the 1985 incidence as the base. ${ }^{8}$ Figure 3.4 shows property crime trends. The pattern of firearm robbery during this period is similar to the patterns of firearm assault and homicide, peaking in 1990 before declining sharply. The general decline in nonfirearm homicide is mirrored by the trend for property crimes and nonfirearm robberies, though the phasing of their decline differs by about two years.

The incidence of firearm robberies peaked in 1990 , at $63 \%$ above the 1985 rate. This peak maintained for twelve months through 1991, before declining sharply through 1996. By 1996, the incidence of gun robberies was $47 \%$ lower than the 1985 index, a decline that substantially outperforms the gun homicide and assault trends. The trend for nonfirearm robberies more closely resembles the firearm crime trends generally. These robberies peaked in 1989 at $37 \%$ above the 1985 rate, and by 1996 declined to a point $25 \%$ below the 1985 rate.

\footnotetext{
${ }^{8}$ The data point for the base year is greater than 100 . The within-year fluctuations require smoothing of the curve based on moving averages of six-month periods. Thus, the initial data point actually includes the index for 18 months, or from January 1985 through June 1986.
} 


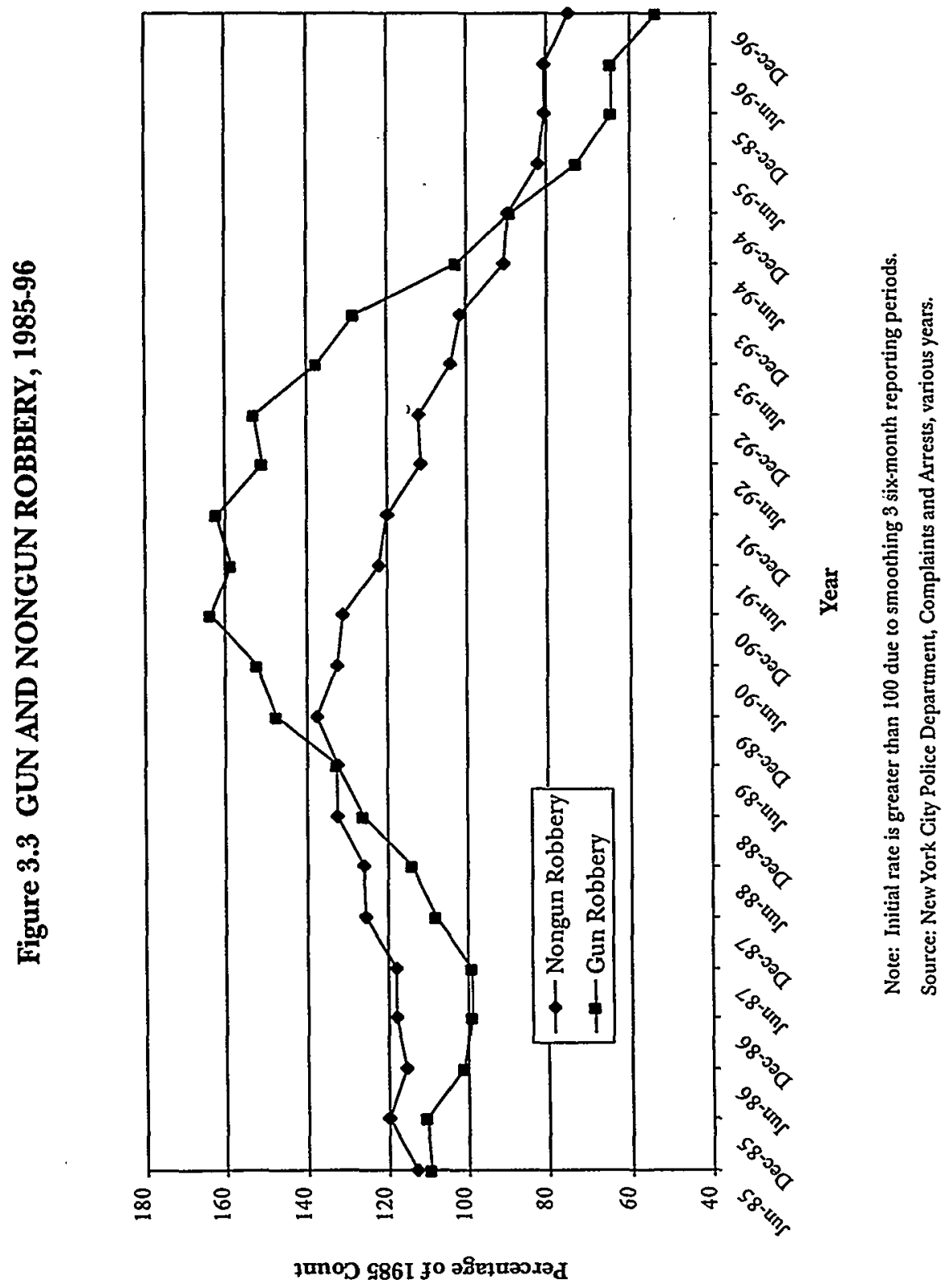


At first glance, this trend appears to contradict the "two trends" finding from the homicide and assault data. One could conclude that these data portray a more unitary violence phenomenon during the period, with rates rising and falling in concert. However, there are two objections to this coupling of firearm and other robberies in a general violence trend. First, the robbery trend beginning in 1989 mirrors identically the "two trends" conclusion in homicides. From a high in 1989, nonfirearm robberies began an uninterrupted decline to an incidence $52 \%$ below the peak. Thus, what differs in the robbery trends is the phasing of the trend, not its shape or magnitude. Though beginning somewhat later, the decline in nonfirearm robberies is otherwise quite similar to the decline in nonfirearm homicides.

Second, robbery itself is a heterogeneous crime, with acts ranging from chain snatching to threats or acts of violence to take property from a person. The growth in nonfirearm robberies from 1985-1989 may reflect a reclassification of borderline cases similar to the nonfirearm assault trends. That is, theft or larceny (without force) cases could be reclassified as robberies in circumstances where threats may be reported. As we show in Figure 3.4, the incidence of larcenies rose slightly during this period, suggesting a general trend of property crime increases that may confound these two crime categories.

Property crime trends are shown in Figure 3.4. Motor vehicle theft spiked in 1989 at over $150 \%$ of its 1985 incidence, before declining precipitously through 1996. By 1996, auto theft was $25 \%$ below its 1985 rate, and nearly two-thirds below its peak incidence in 1988. Burglary trends declined steadily throughout the period, part of a long-term trend in burglary that dates back to the late 1970s. The incidence of burglary in 1996 is $50 \%$ lower than the 1985 incidence. ${ }^{9}$

Larceny patterns, by comparison, are very stable, rising only

${ }^{9}$ Data on insurance claims confirm the decline in reports of auto theft and residential burglary. We obtained information from State Farm Insurance, the third largest underwriter of both automobile and homeowners insurance policies in New York City, on claims and settlements from 1991-1995. The number of claims declined $46 \%$, and insurance settlements declined by $29 \%$ (unadjusted for inflation). 


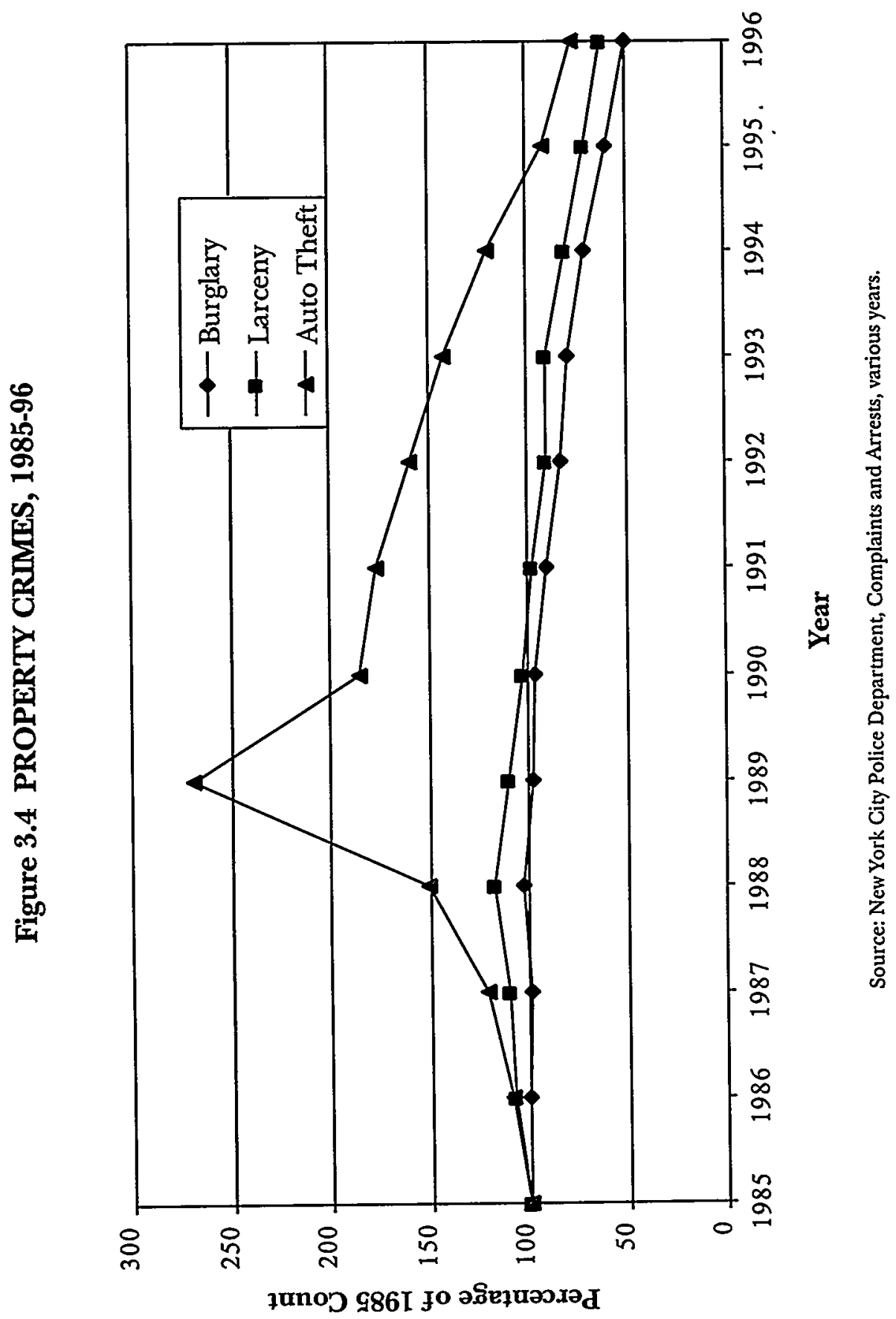


17\% above their 1985 level before declining steadily. By 1996, larceny was $38 \%$ below its 1985 rate, and over $50 \%$ below its peak in 1988. Thus, larceny and nonfirearm robbery trends are close in both shape and phasing. And, though phased three years later, these trends reflect the general nonfirearm crime decline observed earlier. Accordingly, a broad version of a "two trend" theory may be consistent with trends in both robbery and property crimes. The disjuncture between firearm and nonfirearm violence extends to robbery, while the longer-term downward secular trend in nonfirearm crimes now appears to include both violent and property offenses.

\section{SOCIAL TRENDS}

Both popular and social science explanations of the decline of New York homicide rates have focused on important social trends, particularly changes in drug markets and reductions in the population of offenders with the greatest propensity for homicide and gun violence. ${ }^{10}$ There are two reasons that make these explanations particularly attractive. First, homicide and drug epidemics have been closely phased, both temporally and spatially, in New York and nationwide, for nearly thirty years. ${ }^{11}$ Homicide peaks in 1972, 1979, and 1991 mirror three drug epidemics: heroin; cocaine hydrochloride (powder); and crack cocaine. These long-term trends predict that declines in drug use would occur contemporaneously with declines in homicide.

Second, the scale of broader social trends, such as demographic shifts, matches the social scale on which broad crime trends rise and fall. Epidemic theories suggest that declines in the size of the susceptible populations would lead to declines in the incidence of social behaviors whose rapid rise above the

${ }^{10}$ See, e.g., Richard Curtis, The Improbable Transformation of Inner-City Neighborhoods. Crime, Violence, Drugs and Youth in the 1990s, 88 J. CRMM. L. \& CRIMnOLOGY 1233 (1998).

"Jeffrey A. Fagan, Intoxication and Aggression, in M. TONRY \& J. WILSON, DRUGS AND CRIME (Crime and Justice: An Annual Review of Research vol. 13, 1990); Jeffrey A. Fagan, Continuity and Change in American Crime. Lessons from Three Decades, in U.S. DEP'T of Justice, The Challenge of Crime in a Free Soctety: LoOking Back, Looking FORWARD (1998). 
base rate and equally rapid decline illustrate basic epidemic patterns. ${ }^{12}$

Figures 3.5 and 3.6 compare trends in firearm and nonfirearm homicide with trends in both drug activity and population change. We compiled two trends of drug activity: drug overdose deaths, from the records of the Medical Examiner, and trends in drug-related crimes, based on urinalysis results from the Drug Use Forecasting System (DUF). Figure 3.5 shows that the incidence of drug-positive arrestees remains unchanged throughout the period, and is unrelated to both firearm and nonfirearm homicide trends. Moreover, nonfirearm homicides decline steadily throughout the period, and appear to be independent from either drug indicator.

In contrast; drug overdose deaths follow a pattern of short cycles, with relatively brief periods of increase and decline. For example, by 1988, the incidence of drug overdose deaths is $60 \%$ higher than the 1985 base rate. ${ }^{13}$ They fall to $10 \%$ below the base rate in 1990, then rise through 1993 and remain about $40 \%$ above the 1985 incidence.

The rise in drug overdose deaths seems to increase as the incidence of firearm homicide deaths declines. By 1996, the incidence of drug overdose deaths is $21 \%$ above the 1985 base, while firearm homicide deaths are $22 \%$ below the 1985 base. Beginning in 1990, the mortality rate for drug overdose deaths rises from below 10 per 10,000 persons in 1985, peaks at 16 per 100,000 in 1993, and remains stable at 14.3 in 1996. During this period, the homicide fatality rate drops from over 30 deaths per 100,000 to 16.1 in 1996. Indeed, as Richard Curtis and others have pointed out, drugs such as heroin and ketamine supplanted crack as the favored street drug. ${ }^{14}$ These drugs are

\footnotetext{
${ }^{12}$ KENNETH J. ROTHMAN, MODERN EPIDEMIOLOGY (1986); Colin Loftin, Assaultive Violence as a Contagious Process, 62 BUII. OF THE N.Y. ACAD. OF MED. 550 (1986); Malcolm Gladwell, The Tipping Point, THE NEw YORKER, June 3, 1996, at 32.

13 The base year of 1985 is an important year, falling between the earlier emergence of street-level powder cocaine markets and the explosion of crack cocaine in 1986.

${ }^{14}$ Curtis, supra note 10 , at 1266.
} 


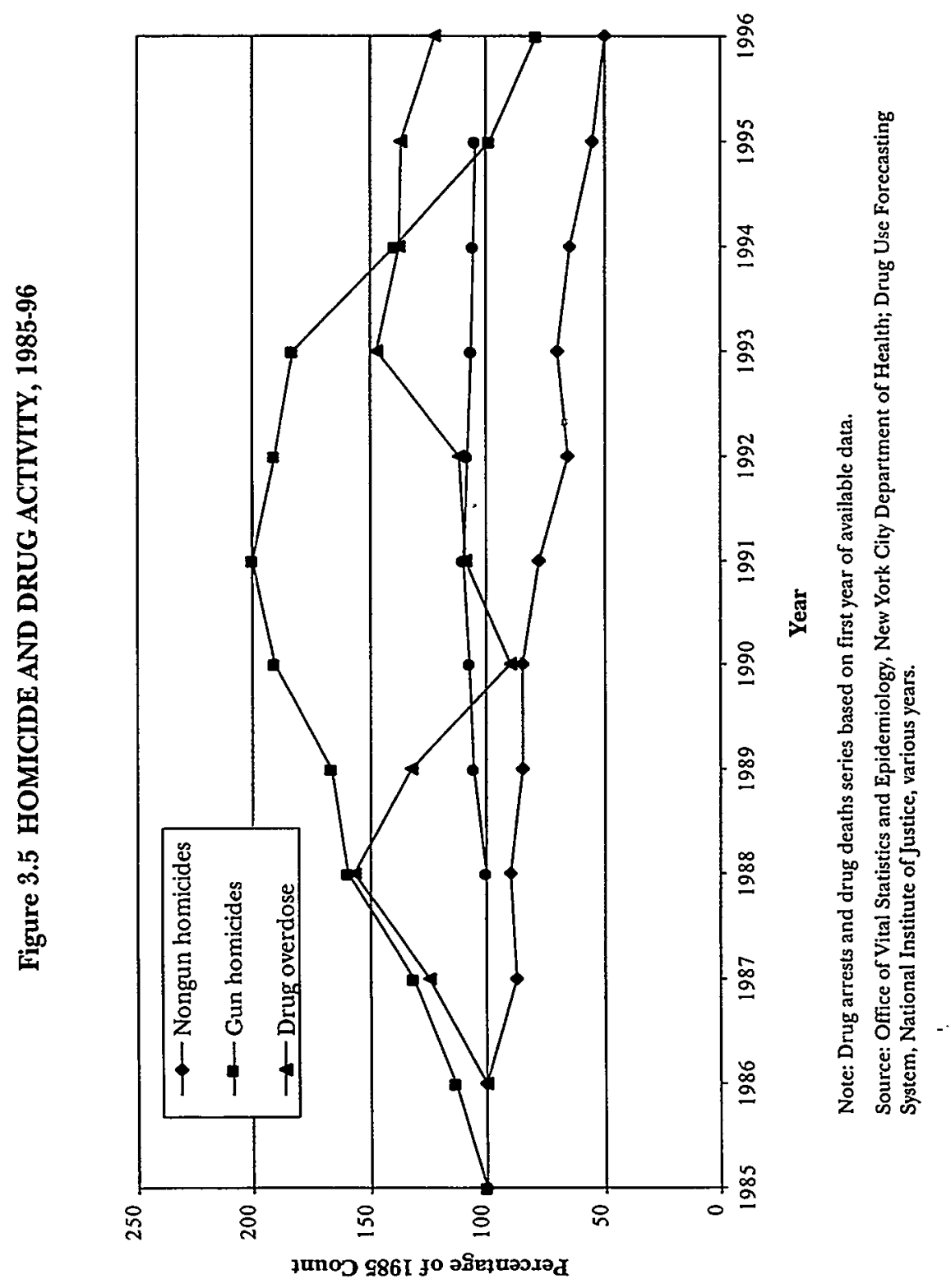


more likely to cause overdose deaths. ${ }^{15}$

What appears as replacement, however, may simply be a spurious relationship between firearm fatalities and drug overdose deaths. Drug use and selling have different correlations with violence, and tend to motivate different types of violence. Homicide rates associated with drug sales rose sharply during the crack era, but violence associated with drug use remained relatively infrequent. ${ }^{16}$ And, although many users were involved in small-scale drug sales, most high-rate drug selling occurred among infrequent drug users. ${ }^{17}$

Accordingly, it is more likely that a decline in street-level drug selling activity may have reduced, to some unknown extent, the types of social interactions that lead to firearm homicides and assaults. It is less likely, however, that high violence drug sellers turned to more lethal forms of drug use.

Figures $3.6 \mathrm{a}$ and $3.6 \mathrm{~b}$ show the trends for firearm and nonfirearm homicides arrayed with population estimates for the subgroups with the highest homicide risk: males 15-29 years of age. $^{18}$ Demographic trends appear to be unrelated to firearm homicides. However, nonfirearm trends appear to coincide with population declines among white and Black males. The population projection for 1995 for Black males forecasts a $17 \%$

${ }^{15}$ Office of Viral Statistics and EPIDEmology, New York GTty Dep't of Health, SUMMARY OF VITAL STATISTICS 1996, THE CITY OF NEW YORK (1997).

${ }^{16}$ Paul J. Goldstein et al., Crack and Homicide in New York City, 1988: A Conceptually Based Event Analysis, 16 CONTEMP. DRUG PROBS. 651 (1989); Jeffrey Fagan, Violence as Regulation and Social Control in the Distribution of Crack, in MARIO DE IA ROSA ET AL., DRUGS AND VIOLENCE (NIDA Research Monograph No. 103, 1990).

${ }^{17}$ See Fagan, supra note 16, at 25.

${ }^{18}$ Population subgroup estimates were obtained from the Current Population Survey for 1985, the U.S. Census for 1990, and population projections completed by the New York Metropolitan Transportation Council for 1995. The latter were developed to predict transportation demand. The population model uses a cohort-survival technique that adjusts for cohort mortality, natality, survival rates and net migration rates at five-year intervals. Population is broken down into age-/sex-/race-specific cohorts using the Census Bureau MARS data set. Separate projections are made for each age/sex/race cohort. Population growth is based on forecasted age-specific fertility rates for females. The net-migration component is a function of historical rates and projected labor force demand segmented by type of job. See N.Y. METROPOLITAN

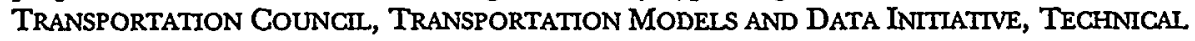
MEMORANDUM No. 8.9: POPULATION FORECASTING AND ANALYSIS (1995). 


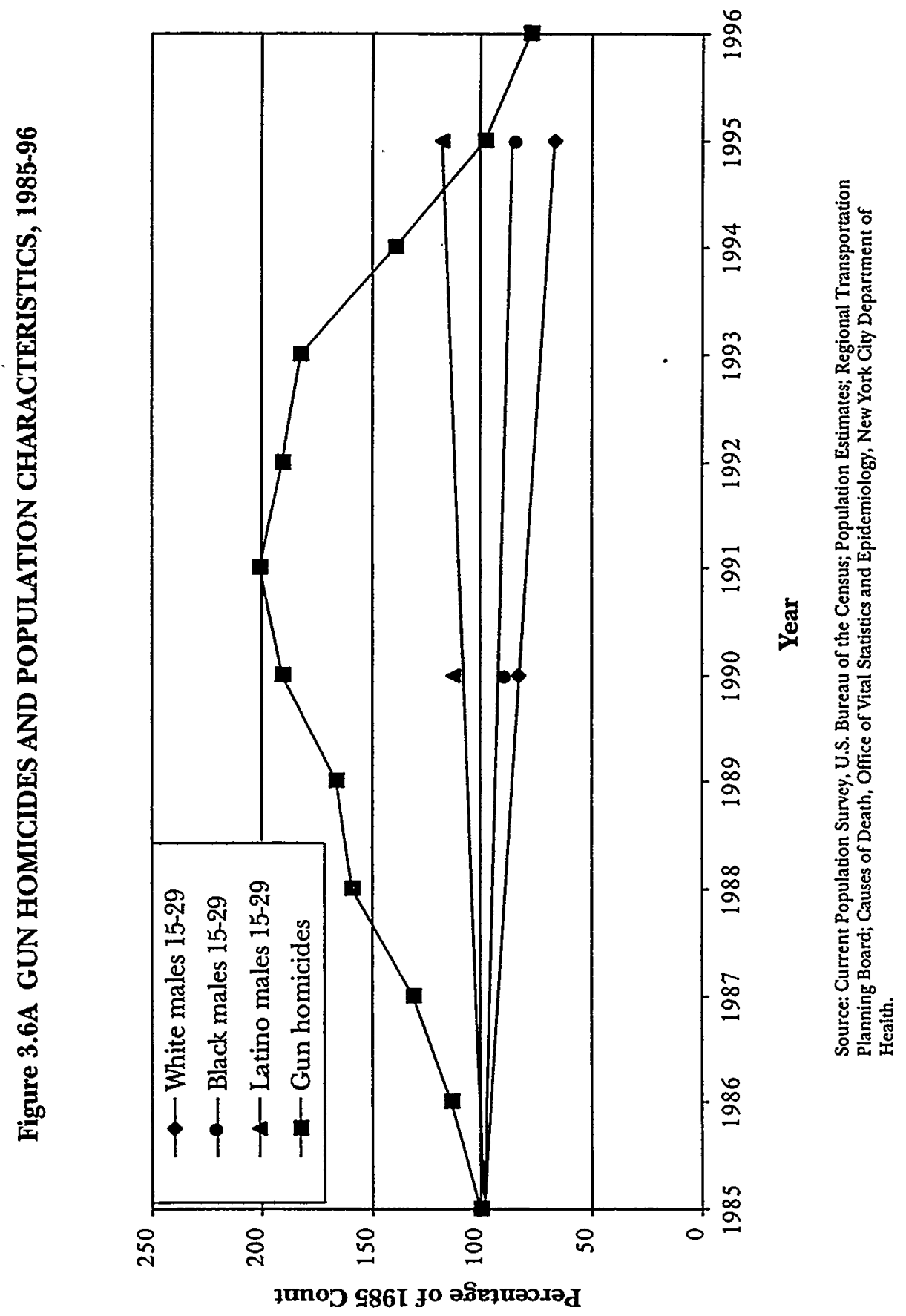




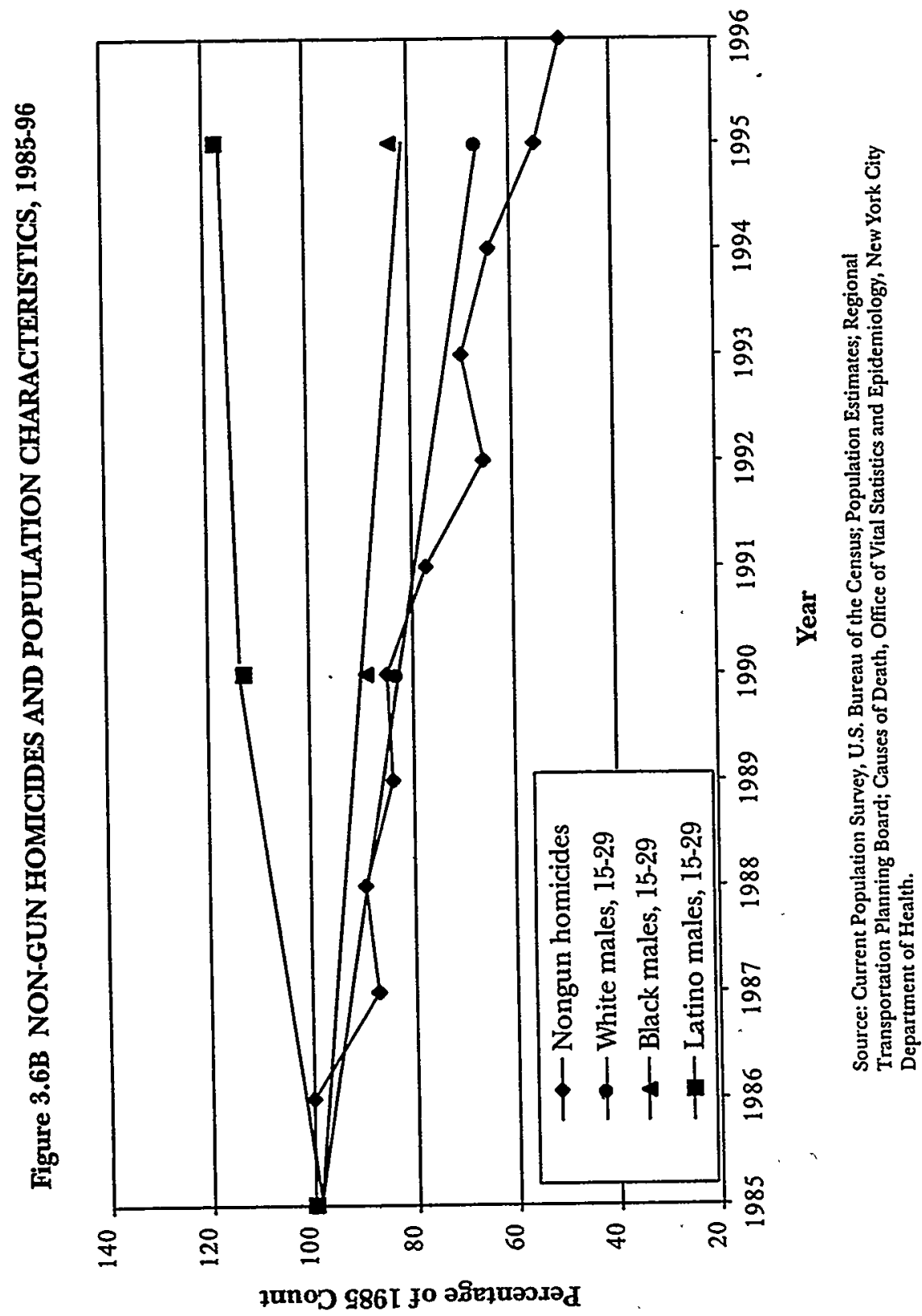


decline among males 15-29 years, or about 41,000 persons in absolute terms. For whites, the decline is sharper: 130,000 fewer males ages 15-29 are estimated to be living in New York City in 1995 than a decade earlier.

Can such declines produce the magnitude of homicide decline observed in this decade? Population declines for the highest risk groups, non-white males ages 15-29, were evident throughout the period, beginning during the increase in firearm homicide and continuing through the period of decline. Accordingly, it is tempting to dismiss demography as a correlate of the homicide decline. However, the relationship of population to a changing behavioral pattern may be nonlinear. ${ }^{19}$ In other words, did the population decline reach a threshold where it could lead to a decline in the incidence of firearm homicides? ${ }^{20}$ This is a plausible but unfalsifiable explanation. Like the effects of declining drug markets, the contraction in the highest risk population is an important but unknowable influence on the decline in firearm homicides from 1992-1996.

\section{LAW AND POLICY}

Significant changes occurred in law and criminal justice during this period to produce important changes in the likelihood of detection and punishment of crime. Rapid expansion

${ }^{19}$ See Gladwell, supra note 12, at 33.

${ }^{20}$ Sustained declines in populations with the highest propensity for lethal violence, males ages 15-29, might weaken their social networks and reduce the extent of social interactions of their members. The social and spatial clustering of homicide suggests that it is concentrated within overlapping social networks in small areas. Jeffrey Fagan et al., Social Contagion of Youth Homicide in New York, in P.J. Cook \& M. Moore, THE EPIDEMIC OF Youth VrolenCE: A SubSTantrve and INIEllectual Chalienge (1998). Social contagion theory suggests that individuals are likely to mutually influence the behaviors of others with whom they are in frequent and redundant contact. RONALD S. BuRT, SOCIAL CONTAGION (1992); Gregory Bovasso, A Network Analysis of Social Contagion Processes in an Organizational Intervention, 49 HUM. REL. 1419 (1996). The social interactions underlying assaultive violence suggest its spread by social contact. See Loftin, supra note 12, at 554. The dissolution of social networks from attrition would reduce opportunities for social transmission of assaultive violence. The relationship of network density to social contagion is nonlinear, however. Thus, epidemiologists discuss thresholds, or tipping points, where behavioral change accelerates and spreads through a population before beginning its process of decline. See, e.g., Jonathan Crane, The Epidemic Theory of Ghettos and Neighborhood Effects on Dropping Out and Teenage Childbearing, 96 AM. J. Soc. 1226 (1991); Gladwell, supra note 12, at 34. 
of prison populations have occurred in nearly every state, including New York. ${ }^{21}$ Moreover, New York City implemented an aggressive policy of street-level enforcement against both drug crimes in the $1980 \mathrm{~s}^{22}$ and "quality of life" crimes in $1994 .^{23}$ In this section, we assess the relationships between these two policy shifts and the trends in homicide.

\section{Policing}

Figure 3.7 shows the trends in policing over the 11-year period. Changes in policing were unrelated to the long-term decline in nongun homicides. This is a secular trend whose explanations lie beyond the hypotheses raised here about post1990 interventions. But there are some apparent links between police resources, firearm killings and crime rates, as well as police strategy and homicide trends. Patrol strength increased from its 1991 count of 6,647 officers to over 8,305 officers in 1995 , an increase of nearly $25 \%$. Figure 3.7 shows that the increase in patrol strength was sharpest from 1991 to 1994, the period of onset of the decline in firearm homicides. In addition, marked shifts in policing strategy began in $1994,{ }^{24}$ concurrent with even sharper declines in firearm homicides from 1994 1996.

The influence of policing on homicide is evident in data on the locations of homicides. The New York Police Department records whether crime events are "visible by patrol"; we used this indicator as a proxy for whether crimes occurred indoors or outdoors. Increased patrol and aggressive patrol tactics should reduce opportunities for visible or outdoor crime commission. Figure 3.8 shows trends in homicides committed indoors and outdoors, again using the 1985 incidence as a base of 100 .

\footnotetext{
${ }^{21}$ Michael H. TONRY, Malign Neglect: RACE, CRIME \& PUNSHMENT in AMerica 5866 (1995).

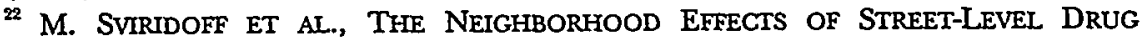

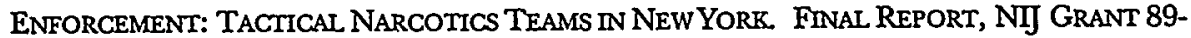
IJ-CX-0056 (1992).

${ }^{23}$ See generally George L. KeIrING \& CatherIne M. Coles, Fixing Broken Windows: RESTORING ORDER AND REDUCING CRIME IN OUR COMMUNITIES (1997).

${ }^{24} \mathrm{Id}$. at 29.
} 


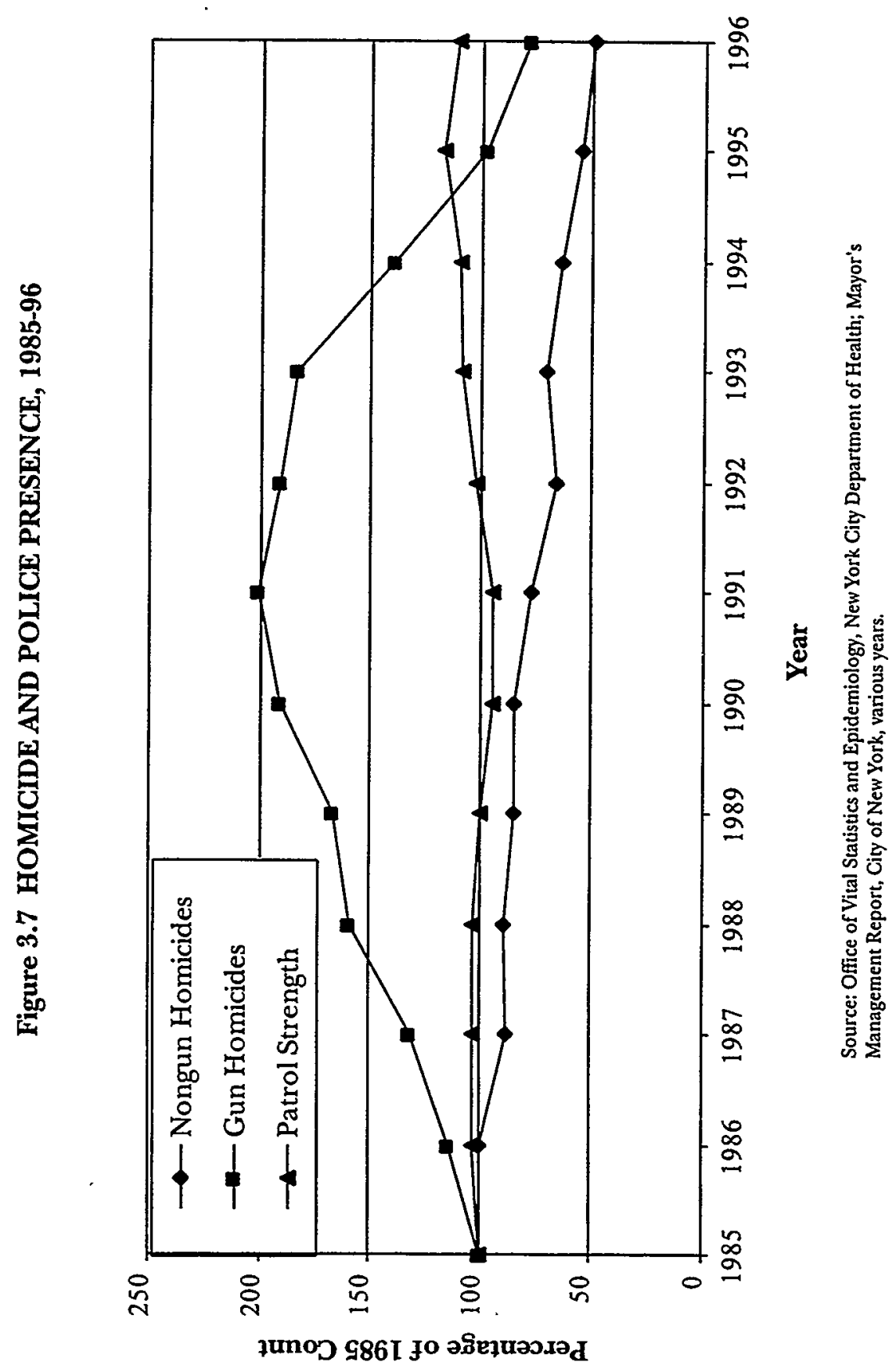




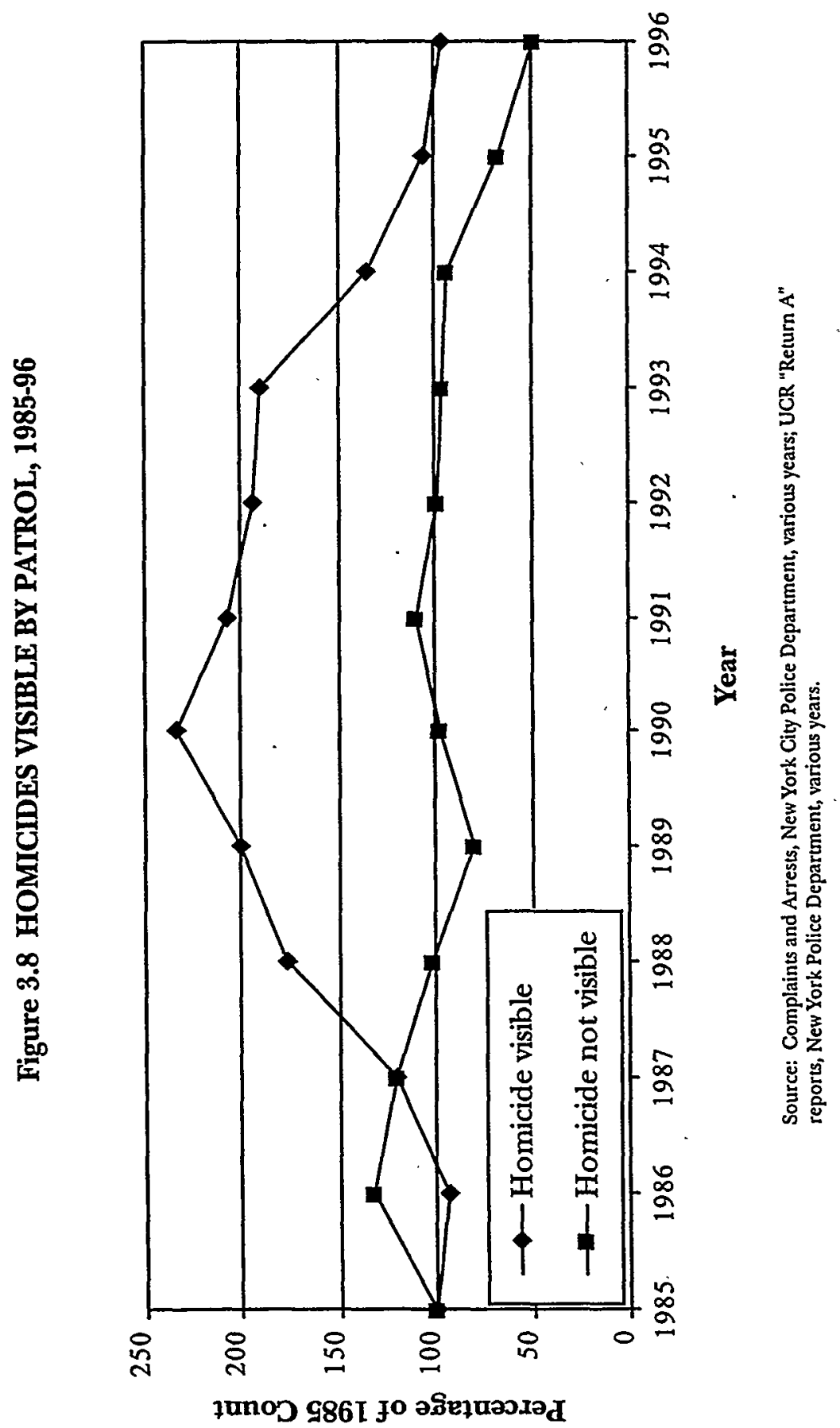


Visible homicides increased rapidly from 1986-1990, peaking at $134 \%$ above the 1985 base rate. There were two periods of decline, from 1991-1993, and a sharper decline from 19941996 when they returned to the 1985 level. After a one-year rise in 1986, nonvisible homicides fluctuated from 1987-1994 before beginning a sharp decline. By 1996, nonvisible homicides were $52 \%$ lower than the 1985 incidence. We find no evidence of displacement from outdoor to indoor homicide in these trends.

This represents a different "two trend" phenomenon with potentially different explanations for two different periods in this decade. From 1991-1994, there were two downward shifts in exogenous events tied to homicides, especially those occurring outdoors. The increase in patrol strength beginning in 1991 might have had a positive effect on reducing visible homicides. The second pressure was tied to changes in the dynamics of drug distribution. The decline in visible homicide was concurrent with the shift from outdoor to indoor drug selling, reducing the volatility of drug transactions and the opportunities for conflicts over money or territory. ${ }^{25}$

The 1994-1996 decline coincides with changes in police strategy. Combined with earlier downward pressures, the shift toward an aggressive enforcement strategy targeted at firearms might have produced sharp declines in both indoor and outdoor homicides.

\section{Incapacitation}

Both city and state incarceration populations are arrayed with homicide trends in Figure 3.9. ${ }^{26}$ During the period of in-

${ }^{25}$ See generally BouRgors, supra note 6 ; Curtis, supra note 10 , at 1262-63. Although the "drug-relatedness" of specific homicides is difficult to determine, the direct and indirect contribution of drug problems to homicide rates has been stable over time. Goldstein, supra note 16 , at 663 . Changes in drug markets, as evidenced by shifts in consumption patterns and marketing styles, should contribute to changes in homicide rates. B.D. Johnson et al., Careers in Crack, Drug Use, Distribution and Non-Drug Criminality, 34 CRIME \& DELINQ. 251 (1995).

${ }^{26}$ Average daily populations are shown for the jail population in New York City, and the year-end census is shown for the New York State Prisons. The percentage of the New York State prison population that was New York City residents at the time of commitment varies from $66.0 \%$ to $73.3 \%$ in 1996 . See generally U.S. Dep't Justice, Bureau of Justice Statistics, Prison Statistics (last modified July 1998) 
creasing firearm homicide rates from 1985 through 1991, prison and jail populations increased at the same pace. Jail populations declined from 1992-1994, a year after the onset of the gun homicide decline. Jail populations then rose again in 1995 as gun homicides continued to decrease. By 1995, jail admissions were $50 \%$ higher than in 1985 . State prison populations rose throughout the period from 1985-1995. By 1991, when the incidence of firearm homicides was highest, state prison populations had doubled the 1985 rate. That is, homicide and state prison populations rose in lockstep through 1991, and continued to rise even as firearm homicides, and homicides overall, began their rapid decline.

While firearm homicides and homicides generally began their decline in 1992, state prison admissions continued to rise. By 1993, they were nearly $150 \%$ higher than the 1985 rate, and about $50 \%$ higher than the rate at the 1991 peak of the incidence of homicide and other firearm-related crimes.

The extent to which these legal policies influenced homicide trends differs by policy domain. Incarceration trends seem to be unrelated to homicide trends. There appears to be a negative correlation between police strength and firearm homicide, but the significance of these effects, or their primacy in relation to social influences, is not knowable. The effects of both manpower and tactical changes in policing may well be important and strong contributors to the homicide decline. However, the magnitude and timing of the decline in firearm homicides is so great as to require additional, contemporaneous explanations and effects that no doubt interact with policing to produce unprecedented change.

$<$ http://wwww.ojp.usdoj.gov/bjs/prisons.htm>; Bureau of Justice Statistics, U.S. Dep't Justice, National Corrections Reporting Program: Prison Admissions, Search of 1985-1996 Data Archives of the Inter-University Consortium for Political \& Social Research (Jan. 13, 1999); New York STATE DeP'T Correctional ServS., HUB System: Profile of INMATE POPULATION UNDER CUSTODY ON JANUARY 1, 1997 (1997). New York City residents accounted for $4.1 \%$ of all U.S. prison admissions from 1992-1996. Search of National Corrections Reporting System Reporting System 1992-1996 Archives (Jan. 13, 1999). 


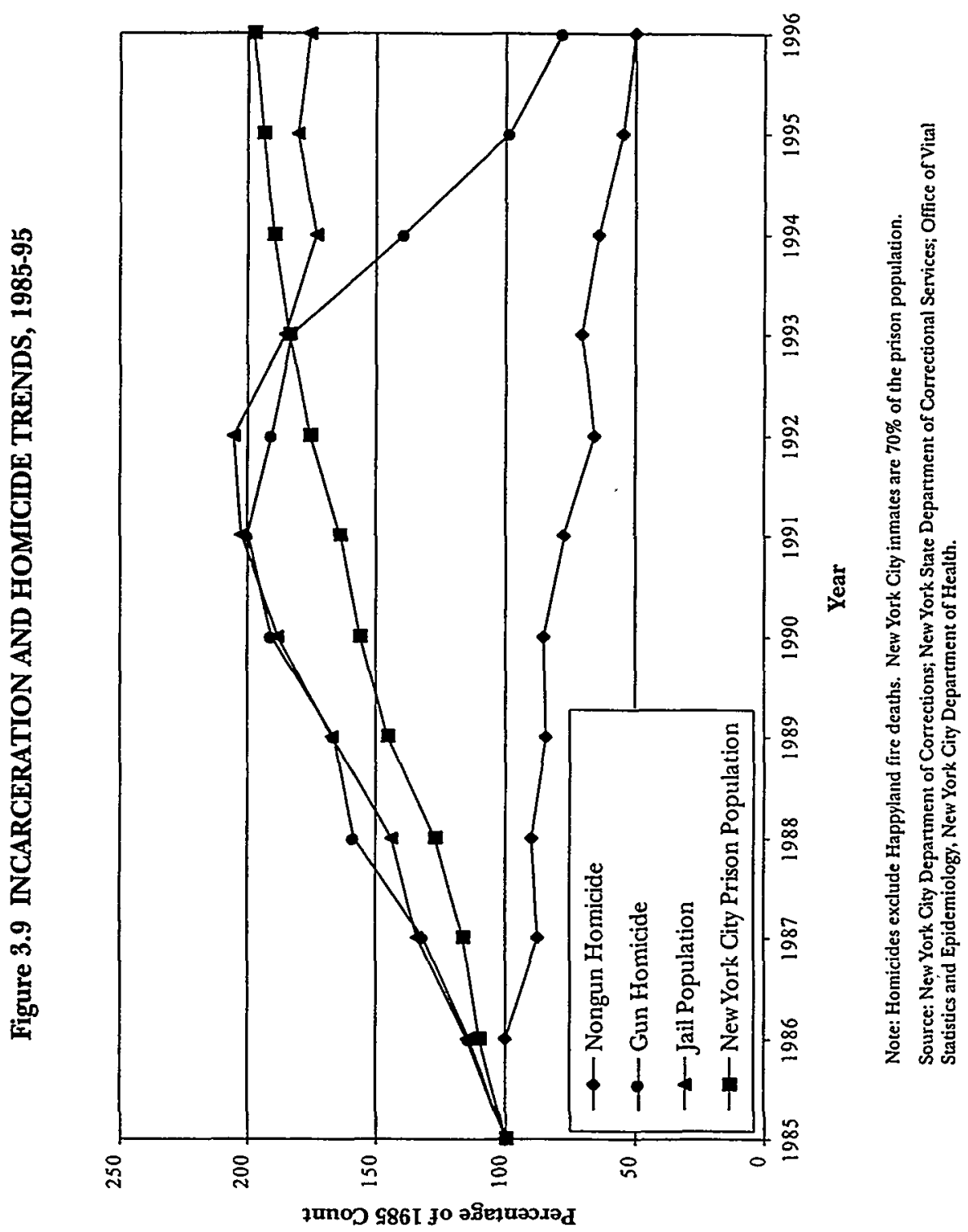




\section{CONSIDERIng CAUSES}

The identification of two separate types of homicide with two discrete time trends is a major complication to theories that wish to identify discrete causes of reduced violence and crime in New York City. In this brief concluding note, we give our own interpretation of how the "two trend" conclusion of this study might be particularly relevant to the frequently voiced theory that changes in policing that occur early in the 1990s are an important explanation of declines in New York homicide.

We start with our negative conclusion. The consistent decline in nongun homicide identified in Part II starts too early and continues too evenly throughout the period under study to have any plausible linkage to changes that come into the city two or three years into the 1990s. Indeed, the evenness of the decline across a decade suggests the influence of an accretive process rather than any sudden step-function change in the environment of New York city homicide was responsible for cutting the nonfirearms homicide rate by half.

However, some important process is involved. There was no indication of regression in this pattern because there was no steep increase prior to 1985 in nongun homicide. Further, the rate of nongun killing is much lower by 1992 than at any time in the previous 15 years. The single or multiple processes that explain the decline in nongun homicide in New York City happened too early to be in the design perspective of this research, but they are no less important for that reason.

The more difficult question is whether the expansion in police resources and changes in the way these were used were major causes of the decline in gun homicide in New York City. The temporal fit between policing changes and gun homicide declines is a good one. Gun homicides begin to decline in the Medical Examiner's count in 1991, but the declines were not large prior to 1994. Because of the steep increase in the gun homicide rate through the late 1980 s, some regression would be expected from peak rates in 1990. So the initial declines in gun killings could be put aside as probable regression leaving the $85 \%$ of the drop that happens after 1993 as gun homicide declines that could have been produced by changing patterns of 
policing in the city. We must also recall that police strength, without new tactics, began a measurable climb at the same time that firearm homicides began their decline. These colliding forces produced a decline of unprecedented proportions that continued through 1996 and beyond.

\section{A. REGRESSION REVISITED}

A little bit of regression might make the causal role of policing more likely, but regression is also a competing explanation for the large drops in gun homicide after 1993. In Part I of this analysis, the hypothesis that the total decline in New York City homicide was attributable to regression was all but rejected because the decline by 1996 was to a level much lower than the city's long-term average rate, and homicide rates were lower also than the lowest previous level experienced in the past two decades. More than regression must have been at work when the totality of the city's homicides are combined into a single trend.

But once nongun and gun homicide patterns are separated, the regression explanation for gun homicides is more difficult to reject. Figure 4.1 charts two decades of homicide volume in New York City, separately for gun and nongun deaths.

To use a term introduced in Part I, the pattern of gun killings does rather resemble the shape of a rollercoaster, with an ascent through the late 1970 s to a relatively low peak, a return to near the previous low point, a sharp increase to a high peak in 1990 and a precipitous drop thereafter. What makes the regression explanation harder to reject for gun cases is that the 1996 low point is not that far removed from 1978 and 1985 levels of gun homicide.

There is no rigorous method available to parse causal responsibility between law enforcement, social trends, and regression for the city's gun homicide record. All contributed to the decline, all were probably significant. What makes us reluctant to dismiss the law enforcement role is the sharp decline also noted in Part III in gun assault and gun robbery. These two offenses may also reflect cyclical regression but the broad pattern 


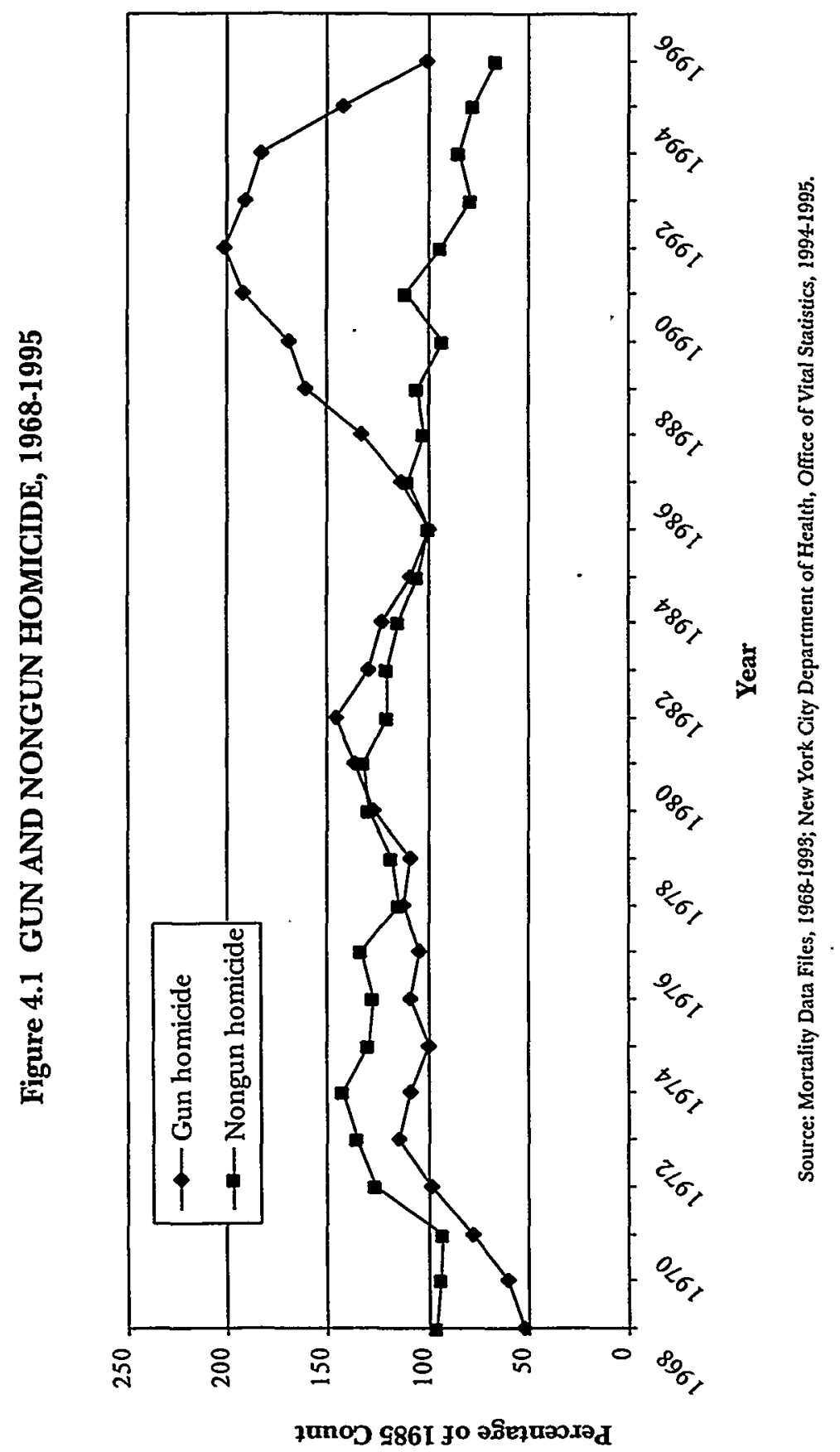


and similar magnitudes are consistent with a substantial environmental change. So while the entire gun homicide drop of 1991 to 1996 is within the boundaries of regression possibility, the more prudent view is to regard the convergence of cyclical variation, social trends in risk and exposure, and law enforcement changes as jointly responsible for a $60 \%$ decline in gun deaths in five years time. How much of the decline can be claimed by law enforcement alone simply cannot be determined.

Related to the problem of apportioning responsibility between regression, demography, and policing for the decline in homicide, a substantial variety of changes in policing are competing to claim credit for positive trends in New York's homicide prevalence: "broken windows" theories of aggressive enforcement, gun interventions, general increases in police enforcement resources, strategic targeting of police efforts through computer mapping, and precinct-level management accountability for crime trends. Was the police share in the happy story graffiti control, squeegee control, gun control, or simply more police?

Because only gun homicide trends are in range to be attributed to police intervention, the case for gun-oriented policing strategies claiming credit is much stronger than for all other policies, but this inference is subject to two qualifications. First, a whole series of street enforcement tactics including stops justified on an order maintenance rationale can have gun-specific results if police use them to produce gun search opportunities. Second, we would also expect regression artifacts in New York City to be much larger for gun cases than nongun cases. So more than the differential success of police gun programs might explain the concentration of trend change after 1992 in the gun cases. Still, the pattern in New York Gity is much more consistent with gun-oriented policing than with indiscriminate qualityof-life interventions as a cause of decline.

The nongun declines are in all probability not the consequence of policing changes or any other process that was not in effect until the 1990s. So one important part of the city's homicide decline was independent of the changes in the 1990s. If 
the origins of the nongun decline were better understood, perhaps we could be more confident about the behavioral explanations of the later gun homicide decline. But with this major reduction in nonfirearms homicide unexplained, there is no good reason to be confident in guessing about the specific causes of the decline in gun killings. The trend in nongun homicide for more than a decade remains a pleasant mystery that shrouds the whole explanation of variations in New York City homicide in fog.

Attributing nongun homicide declines to law enforcement changes was premature and unjustified. Rather than risk more precipitous error in the interpretation of the city's homicide trends, our current understanding of the period from 1985 to 1996 suggests caution. If the downward trend in gun killings continues far past the 1978 and 1985 levels, the probable role of the mid-1990s changes will loom larger with each further decline. If the nongun homicides also continue in their post-1986 pattern, however, even the best statistical data on New York homicide will not yield easy answers on causation. 
